\title{
Bioinspired Intrinsic Control of Freeze Cast Composites: Harnessing Hydrophobic Hydration and Clathrate Hydrates
}

\author{
Steven E. Naleway ${ }^{1}$, Christopher F. Yu ${ }^{2}$, Rachel L. Hsiong ${ }^{2}$, Arijit Sengupta ${ }^{5}$, Peter M. Iovine ${ }^{5}$, \\ John A. Hildebrand ${ }^{3}$, Marc A. Meyers ${ }^{1,2,4}$, Joanna McKittrick ${ }^{1,2}$ \\ ${ }^{1}$ Materials Science and Engineering Program \\ ${ }^{2}$ Department of Mechanical and Aerospace Engineering \\ ${ }^{3}$ Scripps Institution of Oceanography \\ ${ }^{4}$ Department of NanoEngineering \\ University of California, San Diego, 9500 Gilman Drive, La Jolla, CA 92093, USA \\ ${ }^{5}$ Department of Chemistry and Biochemistry, University of San Diego, San Diego, CA, 92110, \\ USA \\ * Corresponding Author: snaleway@eng.ucsd.edu; tel: 1-541-255-9998
}

\begin{abstract}
Bioinspired $\mathrm{ZrO}_{2}$-epoxy, two-phase composite materials were fabricated by the freeze casting fabrication technique followed by polymer infiltration. These materials were intrinsically controlled by adding varying concentrations of the monofunctional alcohols ethanol (EtOH), $n$ propanol $(n-\mathrm{PrOH})$ and $n$-butanol $(n-\mathrm{BuOH})$. The microstructures of freeze cast scaffolds created with these alcohol additives demonstrated maximum pore areas (peak $A_{\mathrm{p}}$ ) at concentrations of $10,5-7$ and $3 \mathrm{vol} . \%$ for $\mathrm{EtOH}, n-\mathrm{PrOH}$ and $n$ - $\mathrm{BuOH}$ respectively. Differential scanning calorimetry analyses of binary mixtures of these additives and water suggested only $n$-PrOH was capable of developing clathrate hydrates. Measurements of the adiabatic compressibility of complete freeze casting slurries showed that a similar room temperature phenomenon, hydrophobic hydration, was occurring in all cases with the maximum effect occurring at the same additive concentrations as the peak $A_{\mathrm{p}}$ values. This highlights that effects occurring within the slurry at room temperature and before freezing may have a significant effect on the freeze casting process. Analysis of the mechanical properties shows that infiltration of the scaffolds can provide resistance to Euler buckling, resulting in strengths of $\sim 3$ orders of magnitude greater than uninfiltrated (and therefore unsupported) scaffolds. This suggests that layered structural design elements, found throughout nature, may be harnessing this Euler buckling resistance to increase strength.
\end{abstract}


KEYWORDS: Freeze-casting; structure-property relationship; hydrophobic hydration and clathrate hydrates; layered structures; mechanical properties 


\section{INTRODUCTION}

Freeze casting has been an attractive area of research in recent years as it offers the potential to fabricate controlled porous microstructures through a simple and inexpensive technique [1-5]. The process itself is carried out in four steps: (1) a slurry of solid loading (e.g. ceramic particles) and liquid freezing agent is prepared along with polymeric binders and dispersants, (2) the slurry is frozen in a directional and controlled manner with the solid loading forming lamellar walls (when $\mathrm{H}_{2} \mathrm{O}$ is used as a freezing agent) [1-5], (3) the frozen scaffold is lyophilized (freeze dried) to remove the freezing agent, where aligned pores result from the sublimated ice crystals, (4) the scaffold is then sintered to enhance its strength. Once fabricated, a fifth, post-processing step can be implemented. One method of post-processing is to infiltrate the bare scaffolds with polymers or metals to create two-phase interpenetrating composites [5-8].

These resultant, composite scaffolds have been fabricated into bioinspired designs similar in structure and properties to bone [9-13] and the nacre of abalone [1, 14]. Biological layered structures such as these are found in successful organisms from deep sea sponges to beetles to humans where they are capable of providing significantly improved mechanical properties due to their hierarchical structuring [15]. Given this success, the study of these bioinspired composites is a field that provides great potential for structural and biomedical applications. While there are many methods to fabricate bioinspired designs, the ability within freeze casting to control the microstructure and mechanical properties of the resultant materials through relatively simple alterations to the processing conditions is key to the potential of the technique. More importantly, freeze casting is capable of harnessing the same fundamental construction method as so many biological materials in templating. Where collagen provides a template for biogenic hydroxyapatite in bone [16] and fish scales [17], the ice itself provides the template for the ceramic of a freeze cast scaffold. By employing this similar technique, the hierarchical structures within biological materials can be easily mimicked and explored.

When considering control of the freeze casting process, an analogy can be drawn to the processes involved with the resistance to crack propagation in fracture mechanics where toughness is imparted through intrinsic (those that occur ahead of a growing crack, occur on smaller length scales and are generally inherent to the material itself) and extrinsic (those that occur in the wake of a growing crack, act on larger length scales and are often controlled by structural features) 
mechanisms $[9,18]$. Similarly, control of freeze casting can also be considered to be by intrinsic (those acting within the slurry that are inherent to its freezing and chemical interactions) or extrinsic (those acting on the freezing process through outside forces) mechanisms.

Recent work into intrinsic control of freeze casting with the monofunctional alcohol isopropanol (IPA) as an additive to the slurry reported the presence of clathrate hydrates in the freezing process leading to enlarged final porosity $[19,20]$. Clathrate hydrates are defined as nonstoichiometric structures where a hydrogen bonded molecule enclosure lattice (made of $\mathrm{H}_{2} \mathrm{O}$ molecules) surrounds a guest molecule (e.g. monofunctional alcohols) with limited or no chemical bonding to the lattice [21]. These structures can be defined by the hydration number, $n_{\mathrm{h}}$, which is defined as the number of $\mathrm{H}_{2} \mathrm{O}$ molecules per guest molecule. Values of $n_{\mathrm{h}}$ vary depending on the guest molecule with most alcohols producing values of $\sim 1-6$. The enlarged unit cells of clathrate hydrates occurring during the freezing process have been shown to contribute to the observed increase in pore area in the final freeze cast scaffold [20]. However, there is still a significant unanswered question in this explanation as the pore area shows a parabolic relationship with the concentration of IPA additive. This is illustrated in Fig. 1, comparing results generated for this study (using the same parameters described below) along with previous studies for $\mathrm{ZrO}_{2}$ [20] and $\mathrm{TiO}_{2}$ [19] scaffolds. To account for the discrepancies in processing parameters, the results in Fig. 1 are normalized to the pore area reported for a scaffold with no additive $\left(0 \mathrm{vol} \% \mathrm{IPA}=A_{\mathrm{p} 0}\right)$. In spite of this, all three trials demonstrated a maximum in pore area, described here as peak $A_{\mathrm{p}}$, at the same concentration of 5 - 7 vol. $\%$ IPA.

In this work we present a homologous series of linear monofunctional alcohols as intrinsic templating additives: ethanol $\left(\mathrm{EtOH}, \mathrm{C}_{2} \mathrm{H}_{5} \mathrm{OH}\right)$, n-propanol $\left(n-\mathrm{PrOH}, \mathrm{C}_{3} \mathrm{H}_{7} \mathrm{OH}\right)$ and $n$-butanol $\left(n-\mathrm{BuOH}, \mathrm{C}_{4} \mathrm{H}_{9} \mathrm{OH}\right)$. EtOH $[22,23]$ and $n-\mathrm{PrOH}$ [24] have been reported to form clathrate hydrates in dilute binary mixtures at low temperatures. While there are no current reports on the presence of clathrate hydrates in $n-\mathrm{BuOH}$, the branched butanol, tert-butyl alcohol has been reported to form clathrate hydrates in dilute concentrations [23]. In addition, we present data and analysis on the mechanics of bioinspired composites created with these scaffolds and are able to provide new insight into the structural support provided by the infiltration of freeze cast materials as well as layered structures in nature. 


\section{MATERIALS AND METHODS}

\subsection{Sample Preparation}

Aqueous slurries were prepared to investigate the effects of linear monofunctional alcohols as additives to the freeze casting process using EtOH (Koptec, King of Prussia, PA, USA), $n$-PrOH (Fisher Scientific, Fair Lawn, NJ, USA) and $n-\mathrm{BuOH}$ (J. T. Baker, Center Valley, PA, USA). Slurries consisting of $15 \mathrm{vol} \% \mathrm{ZrO}_{2}$ powders (200-500 nm diameter) (Sigma Aldrich, St. Louis, MO, USA) were mixed with 1 wt.\% polyethylene glycol (PEG) with a molecular weight of 10,000 g/mole (Alfa Aesar, Ward Hill, MA, USA), 1 wt.\% polyvinyl alcohol (PVA) with a molecular weight of 100,000 g/mole (Alfa Aesar, Ward Hill, MA, USA) and 1 wt.\% of an ammonium polymethacrylate anionic dispersant, Darvan 811 (R. T. Vanderbilt Company, Inc., Norwalk, CT, USA). Slurries were prepared by varying two parameters: the volume fraction ( 0 , $1,3,5,7,10$ and 15 vol.\%) and the additive (EtOH, $n-\mathrm{PrOH}$ and $n-\mathrm{BuOH})$ for a total of 21 slurries. All slurries were ball milled in an alumina grinding medium for $24 \mathrm{~h}$ then degassed under low vacuum for 5-10 min. Samples of approximately $10 \mathrm{~mL}$ of the degassed slurry were poured into a freeze cast mold and frozen at a constant rate of $10 \mathrm{~K} / \mathrm{min}$ using a custom built freeze casting device, as previously described [25]. After freezing, samples were lyophilized in a bench-top freeze dryer (Labconco, Kansas City, MO, USA) at $223 \mathrm{~K}$ and $350 \mathrm{~Pa}$ for $70 \mathrm{~h}$. After freeze drying, the green scaffolds were sintered in an open air furnace for $3 \mathrm{~h}$ at $1623 \mathrm{~K}$ with heating and cooling rates of $2 \mathrm{~K} / \mathrm{min}$. This sintering procedure is similar to procedures reported as effective for $\mathrm{ZrO}_{2}$ scaffolds [20, 25]. This entire process was performed in triplicate to create three full sets of scaffolds (63 total scaffolds) and ensure reproducibility of the current results. In addition, one set of scaffolds were fabricated using the exact procedure described above with 0 , $1,3,5,7,10$ and 15 vol.\% isopropanol (IPA) in order to create a comparison between current and previously reported results (Fig. 1).

Each scaffold was infiltrated with a two-component polymer epoxy, Epoxicure 2 (Buehler, Lake Bluff, IL, USA) by in situ polymerization in order to form a ceramic-polymer composite for imaging and mechanical testing. Samples were immersed in a mixture of liquid monomer and catalyst under low vacuum for 20-30 min in order to force the liquid to infiltrate the scaffold pores. The infiltrated scaffolds were then allowed to polymerize for $24 \mathrm{~h}$. Samples of pure epoxy were simultaneously created to use for comparative analysis of the mechanical properties. 


\subsection{Material Characterization}

All composite scaffolds were observed with scanning electron microscopy (SEM) at $10 \mathrm{kV}$ and a spot size of $3.0 \mathrm{~nm}$ using a Philips XL30 field emission environmental scanning electron microscope (FEI Company, Hillsboro, OR, USA). For SEM preparation, all samples were sputter-coated with iridium using an Emitech K575X sputter coater (Quorum Technologies Ltd., West Sussex, UK). Microstructural measurements of the pore size were performed using ImageJ software (Nation Institutes of Health, Bethesda, MD, USA). In all cases $N=40$ measurements were taken in order to calculate the mean and standard deviation. Measurements of pore size and shape were performed by adjusting the threshold of the micrographs (using a consistent threshold for all measurements) so as to fit an ellipse to the pores in order to determine the elliptic major axis, $a$, and minor axis, $b$. The assumption of elliptical pores has been previously employed for scaffolds with similar architecture $[19,20]$ and was supported through observations of the pore shape within the current scaffolds. Pore area, $A_{\mathrm{P}}$, and pore aspect ratio, $X_{\mathrm{P}}$, were calculated as $A_{\mathrm{P}}$ $=a b \pi / 4$ and $X_{\mathrm{P}}=a / b$, respectively. In order to image the characteristic pore structure, samples were taken from the interior of the scaffolds so as to avoid the high-density regions at the edges, top and bottom of the sample.

The $\mathrm{ZrO}_{2}$ ceramic volume fraction, $V_{\mathrm{c}}$, of the final ceramic-polymer composites was calculated from a rule of mixtures for a two-phase composite:

$$
V_{\mathrm{c}}=\frac{\rho_{\mathrm{s}}-\rho_{\mathrm{p}}}{\rho_{\mathrm{c}}-\rho_{\mathrm{p}}}
$$

where $\rho_{\mathrm{s}}, \rho_{\mathrm{p}}$ and $\rho_{\mathrm{c}}$ are the final scaffold, polymer (Epoxicure 2) and ceramic $\left(\mathrm{ZrO}_{2}\right)$ densities respectively. The densities $\rho_{\mathrm{s}}$ and $\rho_{\mathrm{p}}$ were each calculated by dividing the measured weight and volume of cubic samples of roughly $5 \times 5 \times 5 \mathrm{~mm}^{3}$. The mean and standard deviation of seven samples were used to determine the final density. This method assumes that the infiltrated scaffolds are solely two-phase composites and are devoid of any air pockets, an assumption that was supported by SEM observations of the final composite scaffolds. The polymer density was measured to be $\rho_{\mathrm{p}}=1.173 \times 10^{6} \mathrm{~g} / \mathrm{cm}^{3}$ while the density of pure $\mathrm{ZrO}_{2}$ was used, $\rho_{\mathrm{c}}=5.89 \times 10^{6}$ $\mathrm{g} / \mathrm{cm}^{3}$. Measured values of $\rho_{\mathrm{s}}$ ranged from $2.3-3.0 \times 10^{6} \mathrm{~g} / \mathrm{cm}^{3}$. 
Compression testing of the infiltrated scaffold composites was performed using a 3367 Instron materials testing machine (Instron, Norwood, MA, USA) with a $30 \mathrm{kN}$ static load cell at a constant crosshead velocity of $0.005 \mathrm{~mm} / \mathrm{sec}$. Scaffolds were cut into cubic samples of roughly 5 x $5 \times 5 \mathrm{~mm}^{3}$ and compressed in the longitudinal (ice growth) direction. For each scaffold $N=5$ samples were tested in order to calculate the mean and standard deviation. In addition, samples of pure epoxy were tested. The ultimate compressive strength and effective elastic modulus were determined from the maximum stress and linear slope of the stress-strain curves, respectively. As there was some variability in the magnitude of properties between the complete data sets (e.g. EtOH vs. $n$-PrOH scaffold sets), which has recently been shown to be common amongst the microstructure and mechanics of freeze cast scaffolds [26], all mechanical data was normalized:

$$
Q_{\mathrm{N}}=\frac{Q_{\mathrm{i}}}{Q_{0}}
$$

where $Q$ is either the modulus or ultimate compressive strength, $Q_{\mathrm{N}}$ and $Q_{\mathrm{i}}$ are the normalized and measured values for any given additive concentration and $Q_{0}$ is the mean value of the initial scaffold with no additive (0 vol.\%).

\subsection{Differential Scanning Calorimetry}

The phase transformations during freezing of binary mixtures of EtOH-, $n$ - $\mathrm{PrOH}-$ and $n$ - $\mathrm{BuOH}-$ $\mathrm{H}_{2} \mathrm{O}$ were investigated using a Q20 differential scanning calorimeter (DSC) (TA Instruments, New Castle, DE, USA). DSC has been previously used investigate phase transformations during the freezing of binary non-hydrogen bonded liquids (e.g. monofunctional alcohols) and $\mathrm{H}_{2} \mathrm{O}[20$, 22-24, 27, 28]. In these cases, the heating curves are utilized so as to observe the decomposition of phases within the solid. Concentrations of $0,1,3,5,7,10$ and $15 \mathrm{vol}$.\% EtOH, $n$-PrOH and $n$ $\mathrm{BuOH}$ (21 total tests) were tested with heating and cooling rates of $10 \mathrm{~K} / \mathrm{min}$ from room temperature to $213 \mathrm{~K}$ so as to imitate the freeze casting process. This lower temperature limit has been previously shown to be satisfactory to emulate the conditions within the freeze casting process [20].

\subsection{Sound Velocity and Hydration Measurements}

Measurements of the liquid density and sound velocity were taken to determine the influence of room temperature effects on the freeze casting process. Two complete sets of liquid freezing agents were created each with concentrations of $0,1,3,5,7,10$ and 15 vol.\% EtOH, $n$-PrOH and 
$n$-BuOH (21 total samples per set). One set included only binary mixtures of alcohol and water, to reproduce previous results [29-31] and ensure accuracy of the setup; the other included $1 \mathrm{wt} \%$ PEG, 1 wt.\% PVA, 1 wt.\% Darvan 811 and 15 vol.\% $\mathrm{ZrO}_{2}$ particles so as to mimic the slurry constituents within this study. In addition, as there are no current reports on sound velocity measurements of slurries such as the ones in this study, slurries were also tested to determine the effect of the solid loading particles on the measurements. Two sets of slurries were prepared, one with no additive and one with 7 vol.\% $n$ - $\mathrm{PrOH}$ (which was shown through preliminary testing to have the largest effect on the sound velocity). In each case these were prepared as stated (i.e. including polymers and dispersant) above but with varying solid loading concentrations of 0,5 , 10 and 15 vol. $\% \mathrm{ZrO}_{2}$ particles.

In all cases, the density was calculated by weighing samples of a constant volume $(1 \mathrm{~mL})$. Sound velocity measurements were taken using a USD 10 Ultrasonic Detector (Krautkramer Branson, Lewistown, PA, USA) with a system delay of $1.092 \mu$ s and input intensities of 10-25 dB and 55$100 \mathrm{~dB}$ for samples without and with solid loading respectively. Five measurements were taken on each sample to calculate the average and standard deviation.

\section{RESULTS AND DISCUSSION}

Microstructural and mechanical properties of the scaffold composites are given for EtOH (Table 1), $n$-PrOH (Table 2) and $n-\mathrm{BuOH}$ (Table 3) as a function of the additive concentration. The largest effect of each additive, as measured by the highest magnitude of $A_{\mathrm{p}}$, is identified as the "peak $A_{\mathrm{p}}$ " and is given in bold in Tables 1-3. This notation is employed throughout the discussion and analysis in this manuscript. The peak $A_{\mathrm{p}}$ value for $n-\mathrm{PrOH}$ in $\mathrm{ZrO}_{2}$ based freeze cast scaffolds occurs at 5 - 7 vol.\%, the same value observed for experiments performed on IPA (Fig. 1) $[19,20]$. However, the peak $A_{\mathrm{p}}$ values for $\mathrm{EtOH}$ and $n-\mathrm{BuOH}$ in $\mathrm{ZrO}_{2}$ based freeze cast scaffolds occur at 10 and 3 vol.\% respectively. This is displayed graphically in Fig. 2a where it can also be seen that the peak $A_{\mathrm{p}}$ in $n$-PrOH produces the highest magnitude of the three additives. Similarly, $X_{\mathrm{p}}$ (Fig. 2b) presents the same maxima, though the maxima observed for $n$ $\mathrm{BuOH}$ is relatively smaller than their associated peak $A_{\mathrm{p}}$. Micrographs of each additive are displayed in Fig. 3. In each case, the baseline microstructure with no additive ( 0 vol.\%) and microstructures with 1 and 15 vol.\% are displayed along with the microstructure of the scaffold at the peak $A_{\mathrm{p}}$. As expected, the baseline microstructures appear very similar given that they have 
the exact same slurry properties. However, from observing the measured dimensions for these samples with 0 vol.\% additive in Tables $1-3$, it can be seen that there is a relatively large variation in the pore size, with mean values of $A_{\mathrm{p}}=752,532$ and $560 \mu \mathrm{m}^{2}$ for EtOH, $n-\mathrm{PrOH}$ and $n$ - $\mathrm{BuOH}$, respectively. This discrepancy can be explained by the inherent variability within the base freeze casting process. It was recently reported that statistically significant variability was found within samples freeze cast with the exact same processing conditions and constituents [26] (as is the case in the 0 vol.\% samples here). This was proposed to be resulting from the inherent variability in the growth of ice, the fundamental templating force within the freeze casting process, which only provides control of the final porosity in one dimension [26]. In addition, at 15 vol.\% each additive displays a collapsed microstructure with pore measurements similar to those at 0 vol.\% (Tables 1-3).

\subsection{The Effect of Clathrate Hydrates}

Results of DSC experiments upon varying concentrations of binary mixtures of the current monofunctional alcohols with $\mathrm{H}_{2} \mathrm{O}$ are shown in Fig. 4 along with the associated phase diagrams, where available. EtOH (Fig. 4a) displays only a single endotherm at $\sim 273 \mathrm{~K}$ that broadens and shifts to slightly lower temperatures with increasing concentration. From the phase diagram, this single endotherm is associated with the decomposition of a solid solution ice phase to a single phase liquid. There are no observed clathrate hydrates forming in these results. $n$-PrOH (Fig. 4b) displays two additional endotherms. The first is found at $\sim 263 \mathrm{~K}$ and is associated with the decomposition of a solid phase, $X$, to a liquid solution. The nature of $X$ is a matter of some debate: Chapoy et al. [32] reported this to be a clathrate hydrate with $n_{\mathrm{h}}=17$ while Manakov et al. [24] have disputed this claim suggesting that it is only a solid solution ice phase. Given the similar DSC curve structure to previous work on the chemically identical IPA, which was shown to result in clathrate hydrate formation [20], we suggest that clathrate hydrates are present in this system as well. $n$ - BuOH (Fig. 4c) displays a sharp endotherm at $273 \mathrm{~K}$. The steep nature of this endotherm at concentrations above 3 vol.\% is suggested to be associated with the solubility limit of $n-\mathrm{BuOH}$ in pure $\mathrm{H}_{2} \mathrm{O}$ at $\sim 3$ vol.\%. Additionally, due to the limited solubility, to our knowledge, no phase diagrams are available for the binary $n$-BuOH-water system. Regardless, the lack of a second endotherm at temperatures lower than $273 \mathrm{~K}$ (which is associated with the decomposition of pure ice) negates the possibility of additional clathrate hydrate phases. These results suggest that while there are clathrate hydrates forming during the freeze casting process 
with $n-\mathrm{PrOH}$, there are no strong signs of clathrates forming during the freeze casting process with either $\mathrm{EtOH}$ or $n$ - $\mathrm{BuOH}$. Therefore a different mechanism must be primarily responsible for the scaffold microstructures presented here.

\subsection{Hydrophobic Hydration}

The phenomenon observed in mixtures of hydrophobic liquids (e.g. monofunctional alcohols) with $\mathrm{H}_{2} \mathrm{O}$, called hydrophobic hydration, may hold the key to these results. Similar to clathrate hydrates, hydrophobic hydration occurs in dilute aqueous solutions where a hydrophobic molecule will bond to and/or order and pattern the molecules around itself [33-35]. These structures are referred to as hydrates and, similar to clathrate hydrates, can be defined by $n_{\mathrm{h}}$. Unlike clathrate hydrates, which occur in the solid state and at low temperatures or high pressures, hydrophobic hydration occurs in the liquid state at or around room temperature. While not always associated, the formation of room temperature hydrates has been reported to lead to clathrate hydrate formation upon solidification [36], as diagramed in Fig. 5 for the example of $n$ PrOH. Glinski and Burakowski [29, 31, 35, 37-40] reported in depth on the formation of these structures in binary aqueous solutions of monofunctional alcohols and $\mathrm{H}_{2} \mathrm{O}$. These studies include the monofunctional alcohols examined here that have been reported to form hydrates at room temperature with $n_{\mathrm{h}}$ values of $2.2(\mathrm{EtOH}), 3.1(n-\mathrm{PrOH})$ and $4.0(n-\mathrm{BuOH})$ [35, 37]. The Laplace equation (Eqn. 3) was used to determine the adiabatic compressibility coefficient, $k_{\mathrm{s}}$, as a function of the liquid sound velocity, $c$, and density, $\rho[29,31,35]$ :

$$
\kappa_{\mathrm{s}}=\frac{1}{c^{2} \rho}
$$

The measurement of $k_{\mathrm{S}}$ as a function of the solvent concentration is well known to produce a negative parabolic relationship [30,31]. Previously reported examples of this data for dilute solutions of methanol $\left(\mathrm{MeOH}, \mathrm{CH}_{3} \mathrm{OH}\right), \mathrm{EtOH}$ and $n-\mathrm{PrOH}$ are displayed in Fig. 6a. Similar data for $n$ - $\mathrm{BuOH}$ are only available up to the solubility limit in pure $\mathrm{H}_{2} \mathrm{O}$ of $\sim 3$ vol.\%. As a result, $\mathrm{MeOH}$ is presented to display the relative trends within a homologous series of monofunctional alcohols. As the size of the solute increases (from $\mathrm{MeOH}$ to $n-\mathrm{PrOH}$ ), the additive concentration where the minimum of $\kappa_{\mathrm{S}}$ occurs decreases. This decrease in compressibility can be linked to the process of hydrophobic hydration. The hydrates are relatively more incompressible than pure $\mathrm{H}_{2} \mathrm{O}$, thus lowering the compressibility of the entire solution [35]. As the minimum is 
approached, each additive molecule is fully dispersed and capable of forming an individual hydrate (Fig. 6b). Past the minimum, the liquid becomes saturated resulting in free pockets of the additive solute (Fig. 6c) that increase the compressibility of the solution. As a result, this minimum can be considered to be the saturation point of hydrates within the fluid.

When considering the current series of experiments, it is important to note that many nonelectrolytes can be ordered into homologous series with similar structures but increasing numbers of carbon atoms in their alkyl chains. Within monofunctional alcohols, $\mathrm{MeOH}, \mathrm{EtOH}$, $n$ - $\mathrm{PrOH}, n-\mathrm{BuOH}$ and $n$-pentanol $\left(\mathrm{C}_{5} \mathrm{H}_{11} \mathrm{OH}\right)$ all are linear and increase in length with the addition of methylene groups $\left(\mathrm{CH}_{2}\right)$. Within this homologous series, $n_{\mathrm{h}}$ has been shown to linearly increase when compared to the number of carbon atoms in the non-electrolyte solute [35].

In addition to studies on pure binary mixtures of liquids, suspensions and slurries consisting of a liquid phase and dispersed solid particles have been studied [41, 42]. In order to account for the addition of a solid phase, a modified form of Eqn. 3 can be employed (adapted from [41, 42]):

$$
\kappa_{\mathrm{s}}=\frac{1}{1-\Phi}\left(\frac{1}{c^{2} \rho}-\Phi \kappa_{\mathrm{c}}\right)
$$

where $\kappa_{\mathrm{S}}$ of the isolated liquid phase can be calculated as a function $c$ and $\rho$ measured for the entire mixture as well as the volume fraction of particles in the slurry, $\Phi$, and the adiabatic compressibility of these particles, $k_{\mathrm{c}}$.

Previous measurements of the adiabatic compressibility and hydrophobic hydration have only been performed upon binary mixtures (either liquid-liquid or liquid-solid). However, the slurries of freeze casting are much more complex, containing six constituents (water, alcohol additives, PEG, PVA, dispersant and ceramic solid loading) for the cases examined in this study. While there are undoubtedly many interactions occurring within these mixtures, a simplified analysis of the results can be employed by assuming that the slurries are two-phase mixtures of liquid (i.e. water, alcohol, PEG, PVA and dispersant) and solid ( $\mathrm{ZrO}_{2}$ particles). With this in mind, the sound velocity through the highly incompressible $\mathrm{ZrO}_{2}$ particles (calculated to be $=5976 \mathrm{~m} / \mathrm{s}$ [43]) results in a value of $k_{\mathrm{c}}=5.5 * 10^{-12} \mathrm{~m}^{2} / \mathrm{N}$ (as calculated by Eqn. 3). This is two orders of magnitude smaller than values experimentally calculated for pure $\mathrm{H}_{2} \mathrm{O}, \kappa_{\mathrm{s}} \approx 4.4 * 10^{-10} \mathrm{~m} / \mathrm{N}^{2}$. 
Eqn. 4 accurately assumes that any compressibility experienced by the slurry would effectively result from only the liquid phase, which is also where any effects of hydrophobic hydration would be felt. However, it would be inappropriate to assume that the solid loading has no effect upon the compressibility data. Previous results have shown that, at low concentrations, the sound velocity decreases with increasing solid loading [41, 42]. This would lead to an increase in the compressibility and could result in a significant effect or even inversion of the compressibility measurements taken on full slurries as opposed to the binary mixtures shown in Fig. 6a. This is supported by Horváth-Szabó and Høiland [42], who demonstrated that, in colloidal suspensions, the density and subsequent compressibility of the solid loading is altered by the association of liquid medium to the solid particles. In effect, the density of a solid loading particle, when wetted in a liquid medium, becomes a function of both the original solid body and the liquid attached to it (e,g. penetrating into pores or bound to the surface), thus dispersing the particles and often lowering the effective density. To investigate this, data were collected on two representative solutions $\left(\mathrm{H}_{2} \mathrm{O}\right.$, PEG, PVA, dispersant and alcohol additive) with varied solid loading and plotted in Fig. 7a along with raw data values of $c$ in Fig. 7b and $\rho$ in Fig. 7c. In order to best visualize the effect, the two slurries chosen were a base sample (with no alcohol additive) and the slurry that showed the largest effect on the final microstructure (7 vol.\% $n$-PrOH additive). It can be seen that with the addition of $n-\mathrm{PrOH}$ to the slurry, $k_{\mathrm{s}}$ displays a drastic increase at 15 vol.\% solid loading (the concentration present in this study's slurries). Additionally, it can be seen that, when compared to the base sample, with low solid loading concentrations ( $\leq 5$ vol.\%) the addition of alcohol results in a decrease in $\kappa_{\mathrm{s}}$, corroborating the previous reports on binary mixtures. However, at higher solid loading concentrations $(\geq 10$ vol.\%) this relationship is inverted, with the addition of alcohol resulting in an increase in $\kappa_{\mathrm{s}}$.

This inversion of the relationship between slurries with alcohol and those without can be considered to be the result of a decrease in bulk $\rho$ of the solid loading caused by the presence of hydrates. It has been shown that organic proteins (also known to form hydrates [37]) will increase the stability of slurries and colloids through hydration forces as the proteins coat the solid particles and create a hydrophilic shell [44]. In the current study it is proposed that the hydrates formed by the addition of alcohols can similarly stabilize and disperse the solid loading within the slurries. As previously discussed, when considering the compressibility of a slurry it has been shown that a suspended particle becomes associated with the layer of fluid that 
surrounds it causing a reduction it its effective density $[42,45]$. Such a phenomenon would cause the slurry density to decrease as the total particle surface area increases and therefore (due to the inverse relationship between density and $\kappa_{\mathrm{S}}$ described in Eqn. 3) causing an increase in $\kappa_{\mathrm{s}}$. This is supported by density measurements (Fig. 7c) that show that the addition of $n$-PrOH to slurries at higher solid loading concentrations results in a deviation from an increasing linear trend. This deviation is proposed to be the direct effect to hydrophobic hydration creating large fluid layers surrounding the solid loading particles (as diagramed in Fig. 7) and dispersing them.

Measurements of $\kappa_{\mathrm{s}}$ as a function of additive concentration for all slurries are shown in Fig. 8. In each case, the slurries reach maxima in $k_{\mathrm{s}}$ at the same concentrations as their peak $A_{\mathrm{p}}$ (Fig. 2a). Given the results of the previous experiment, these maxima are considered to be linked to the saturation of hydrates due to hydrophobic hydration, with the solid loading causing the largest concentration of hydrates to occur at a maximum as opposed to a minimum as seen for binary mixtures. Importantly, the parabolic response of $\kappa_{\mathrm{s}}$ with respect to additive concentration is able to provide an understanding of the maxima in pore size within the final freeze cast microstructures. This connection could not be fully explained by the simple presence of clathrate hydrates as there are no phases present at the concentrations associated with peak $A_{\mathrm{p}}$ values in any of the cases presented here or in previous reports. However, the largest increase in microstructural properties was observed with the addition of $n$ - $\mathrm{PrOH}$, which was the only additive in this study to that may display the presence of clathrate hydrates.

The current results highlight the effect of hydrophobic hydration on the freeze casting process and provide a new avenue for intrinsic control. As diagramed in Fig. 9, it is suggested that the presence of the enlarged hydrate structures in the liquid slurry ahead of the ice growth results in enlarged ice crystals, which in turn provide for the enlarged freeze cast microstructures described here. There are a multitude of potential additives known to form hydrates that could be employed including alcohols, polymers, amines, amides and amino acids [37]. One additive of note that is present in the current slurries is the PVA. PVA is employed here as a polymeric binder and is itself known to form a hydrate with $n_{\mathrm{h}} \approx 2$ [37]. Hydrates formed by PVA in aqueous mixtures have been shown to avoid freezing, even at temperatures lower than the normal freezing point [46]. Therefore, the presence of PVA within the slurries used here and in many other freeze casting procedures is likely to result in enlarged porosity due to the same effects of hydrophobic hydration that have been shown to occur here due to the presence of monofunctional alcohols. As 
the proportion of PVA was held constant in all of the experiments described here, no conclusions of the specific effect can be drawn, though future studies into its specific effect could provide valuable insight. However, of greatest importance, this new work suggests that when considering the freeze casting process, attention should be given to the state of the slurry at room temperature, not just to the frozen or freezing states.

\subsection{Mechanical Characterization}

Mechanical properties as a function of additive concentration are shown in Fig. 10. Ultimate compressive strength (UCS, Fig. 10a) and effective compressive modulus (E, Fig. 10b) are both displayed in a normalized form as described in Eqn. 2, allowing for clear comparison of how the trends are affected by the additives. The mechanical properties at the peak $A_{\mathrm{p}}$ for each additive are defined as, $\mathrm{EtOH}(E=4.5 \mathrm{GPa}, U C S=147 \mathrm{MPa}), n-\mathrm{PrOH}(E=3.3 \mathrm{GPa}, U C S=131 \mathrm{MPa})$ and $n-\mathrm{BuOH}(E=4.0 \mathrm{GPa}, U C S=162 \mathrm{MPa})$, this data is taken as the average of five measurements. Representative stress-strain curves from individual experiments for the three peak $A_{\mathrm{p}}$ samples are shown in Fig. 11. In all cases it can be seen that initial failure occurs with little plasticity, however the samples are able to hold a relatively high amount of stress after failure, thus increasing the overall toughness of the samples. The plateau that occurs after the initial failure (which holds a stress of $\sim 75-85 \mathrm{MPa}$ ) is similar to the measured strength of the infiltrating epoxy (with a measured mean value of $79.9 \mathrm{MPa}$ ). Therefore, the ceramic lamellar walls withstand the initial stress up to failure, then the second epoxy phase withstands the majority of stress, with the remaining and unbroken lamellar walls failing one-by-one, until final catastrophic failure. This, multi-step failure mechanism is similar to the "graceful failure" that is characteristic of many porous and cellular materials [47] where a porous material will sustain an initial high stress, then a long plateau as individual porous regions fail with increasing strain. This failure mode is also found in biological materials such as the spines of the slate pencil sea urchin where, due to this mechanism, the toughness of the urchin's calcite spines is significantly higher than that of monolithic calcite [17, 48]. EtOH shows little change in mechanical properties regardless of concentration. Both $n$-PrOH and $n-\mathrm{BuOH}$ display peak values in mechanical properties at the same concentrations associated with their peak $A_{\mathrm{p}}$ 's, with the greatest increase in both $U C S$ and $E$ occurring with the addition of $n-\mathrm{PrOH}$. This shows that any increase in mechanical properties is most closely tied to the magnitude of $A_{\mathrm{p}}$. Of note, the relative magnitude of the increase in mechanical properties from 0 vol. $\%$ to the maximum at 5 
vol.\% for both $U C S$ ( 1.5 times increase) and $E$ ( 2.5 times increase) are similar to those previously reported for similar $\mathrm{ZrO}_{2}$ scaffold composites that used IPA as an additive [20].

While the addition of $\mathrm{EtOH}, n-\mathrm{PrOH}$ and $n-\mathrm{BuOH}$ are capable of realizing an increase in the mechanical properties the exact physical phenomena that drives this is yet unknown. Given that the scaffolds are $\mathrm{ZrO}_{2}$ ceramic-epoxy two phase composites, the mechanical properties were analyzed by a simple rule of mixtures (Eqn. 5), given the relative volume fraction of the ceramic, $V_{\mathrm{c}}$ (Tables 1 - 3).

$$
Q_{\text {comp }}=Q_{\mathrm{ZrO} 2} V_{\mathrm{c}}+Q_{\text {epoxy }}\left(1-V_{\mathrm{c}}\right)
$$

where $Q_{\text {comp }}, Q_{\mathrm{ZrO} 2}$ and $Q_{\text {epoxy }}$ are the mechanical properties ( $E$ and $U C S$ ) of the composite scaffold, $\mathrm{ZrO}_{2}$ (for solid tetragonal $\mathrm{ZrO}_{2}, E_{\mathrm{ZrO} 2}=210 \mathrm{GPa}, U C S \mathrm{ZrO}_{2}=1200 \mathrm{MPa}$ [49]) and epoxy (measured to be $E_{\text {epoxy }}=1.8 \mathrm{GPa}, U C S_{\text {epoxy }}=79.9 \mathrm{MPa}$ ) respectively. These results were found to be significantly in excess of the experimentally measured maximum values with $E=55$ - $70 \mathrm{GPa}$ and $U C S=360-450 \mathrm{MPa}$. This shows that the true fracture behavior cannot be explained with such a simplistic model.

When considering these lower than expected mechanical properties, the fracture mechanisms of each of the two phases must be considered. The rule of mixtures would suggest that both fail in pure compression. While this would be reasonable for a ductile and isotropic material such as the epoxy, it is much less so for the brittle $\mathrm{ZrO}_{2}$, which takes on the form of tall, slender and lamellar walls upon freeze casting. Porter et al. [19] developed a simplified but effective model for uninfiltrated scaffolds of a similar structure that showed the low mechanical properties of were the result of Euler bucking of the lamellar walls. This model accurately predicts the diminishing mechanical properties of uninfiltrated scaffolds as the pore aspect ratio increases by analyzing a unit cell of constant material volume. Observing the current results, failure of the brittle $\mathrm{ZrO}_{2}$ lamellar walls is assumed to again occur by Euler buckling. However, the infiltrating epoxy provides an unknown level of resistance to buckling. A simplified estimation of this resistance to buckling can be determined by calculating the buckling mode, $n$, which corresponds to the number of fixed restraints (or buckling lobes) providing resistance to a column under axial compressive loading [50]. As it is clear that these $\mathrm{ZrO}_{2}$ walls are unable to buckle freely, $n>1$. However, given that $E$ of $\mathrm{ZrO}_{2}$ is almost two orders of magnitude larger than that of the epoxy, it would also be inappropriate to consider the interface between the two phases to be rigidly fixed, 
which would allow the composite to provide properties closer to the rule of mixtures analysis presented above. Therefore, an analysis of the effective $n$ for the composites in this study will be presented. This analysis focuses upon the strength $(U C S)$ of the composite materials at the peak $A_{\mathrm{p}}$ for each alcohol additive. This was done so examine the failure modes of those materials that, experimentally, provided the highest mechanical properties and would be the most likely candidate for structural applications.

To understand this interaction between the two constituents, a simplified model of the current freeze cast composites is assumed as a layered composite (Fig. 12). With this assumption, the strength, total ultimate compressive strength, $U C S_{\mathrm{T}}$, of a $5 \times 5 \times 5 \mathrm{~mm}^{3}$ sample (to match the physical testing) can be calculated by a rule of mixtures that incorporates the failure modes of each constituent: compression for the epoxy and buckling for the $\mathrm{ZrO}_{2}$ ceramic, which is dependent upon the number of ceramic lamellar walls, $N_{\mathrm{w}}$, within the sample:

$$
U C S_{\mathrm{T}}=U C S_{\text {epoxy }}\left(1-V_{\mathrm{c}}\right)+U C S_{\mathrm{Zro2}}\left(N_{\mathrm{w}}\right)
$$

where $U C S_{\text {epoxy }}$ is assumed to be constant in all cases as the experimentally calculated value of $79.9 \mathrm{MPa} . U S_{\mathrm{ZrO} 2}$ is defined as the critical stress for Euler buckling [50]:

$$
U C S_{\mathrm{ZrO2}}=U C S_{\mathrm{wall}}=n^{2} \frac{\pi^{2} q^{2} E_{\mathrm{ZrO2} I} I}{A_{\mathrm{w}}(k l)^{2}}
$$

where $q$ is a previously suggested empirical correction factor in order to incorporate experimental variability such as internal wall porosity and surface roughness (for this case and has been previously used [19], $q=0.02$ ), $I$ is the moment of inertia of the lamellar wall (Eqn. 8), $A_{\mathrm{w}}$ is the cross-sectional area of the wall, which is equal to the wall width, $w(=5 \mathrm{~mm})$, times the wall thickness $T_{\mathrm{w}}$ (experimentally measured ranging from $\sim 6-20 \mu \mathrm{m}$ ), $k$ is a constant that depends on the geometry of the ends (for this case, $k=0.5$ for fixed ends) and $l$ is the wall length ( $=5 \mathrm{~mm}$, all geometries are imaged in Fig. 12a). The moment of inertia, $I$, is:

$$
I=\frac{w T_{\mathrm{w}}^{3}}{12}
$$

The critical stress of buckling is calculated for a single wall. Therefore, the total stress of the numerous walls within the samples cannot be calculated as a simple volume fraction and must be considered to be additive. For this reason, $N_{\mathrm{w}}$ in each scaffold was estimated based upon the known volume fraction of $\mathrm{ZrO}_{2}$ and the experimentally measured wall thickness: 


$$
N_{\mathrm{w}}=\frac{V_{\mathrm{c}} w}{T_{\mathrm{w}}}
$$

Substituting Eqns. 7 - 9 into Eqn. 6, a final simplified model for the strength of the composite scaffolds that takes into account the varying failure modes is developed:

$$
U C S_{\mathrm{T}}=U C S_{\text {epoxy }}\left(1-V_{\mathrm{c}}\right)+n^{2} \frac{\pi^{2} q^{2} E_{\mathrm{ZrO2} 2} w V_{\mathrm{c}} T_{\mathrm{w}}}{12(k l)^{2}}
$$

Finally, Eqn. 10 is rearranged in order to solve for the effective resistance to buckling, $n$ :

$$
n=\frac{k l}{\pi q} \sqrt{\frac{12\left(U C S_{\mathrm{T}}-U C S_{\mathrm{epoxy}}\left(1-V_{\mathrm{c}}\right)\right)}{E_{\mathrm{ZrO} 2} w V_{\mathrm{c}} T_{\mathrm{w}}}}
$$

By setting $U C S_{\mathrm{T}}$ equal to the peak $A_{\mathrm{p}}$ strength values measured for each additive, it was found that $n=18,15$ and 19 for $\mathrm{EtOH}, n-\mathrm{PrOH}$ and $n-\mathrm{BuOH}$ respectively. This represents a high level of interaction and suggests that the infiltration of this second phase, while not able to provide rigid support and ensure compressive failure of the lamellar walls (as would have been predicted by a rule of mixtures), does provide a substantial impact on the mechanical and buckling stability of these structures. To further explore this effect, the UCS of uninfiltrated scaffolds can be calculated from Eqn. 10 by setting $U C S_{\text {epoxy }}=0$ and $n=1$ (denoting a failure of unsupported, mode 1 buckling). This unsupported case predicts very low peak $A_{\mathrm{p}}$ strengths of $0.30,0.32$ and $0.30 \mathrm{MPa}$ for $\mathrm{EtOH}, n$ - $\mathrm{PrOH}$ and $n$ - $\mathrm{BuOH}$ respectively. Of note, these values are similar to those previously reported in experiments on $\mathrm{TiO}_{2}$ freeze cast scaffolds with similar microstructures that utilized IPA as an additive (0.7 MPa) [19]. The results of this analysis are summarized in Fig. 12b.

This analysis demonstrates that, while improved over uninfiltrated scaffolds, the lamellar walls of the current bioinspired composite materials still fail in a buckling mode, thus reducing their strength. In addition, the level of interaction between the two phases can explain the observed increasing trend in mechanical properties with the increase in $X_{\mathrm{p}}$ and $A_{\mathrm{p}}$, which stands in opposition to previous reports of uninfiltrated freeze cast scaffolds $[12,19]$. The dependence of this buckling mode of failure on $T_{\mathrm{w}}$, which generally follows a similar parabolic trend as $A_{\mathrm{p}}$, tends to produce higher strengths with increasing $X_{\mathrm{p}}$ and $A_{\mathrm{p}}$. When attempting to create a stronger material for structural applications, the use of a an infiltrate that more closely matches the elastic properties of the $\mathrm{ZrO}_{2}$ ceramic would provide greater support to the lamellar walls, 
allowing the mechanical properties to approach the elevated properties described by the rule of mixtures analysis.

This level of complex interaction is also present in biological materials with many organisms forming layered structural design elements that consist of numerous interfaces with large changes in mechanical properties, usually resulting from alternating layers of rigid and compliant phases (e.g. ceramic and polymeric respectively) [15]. These are found throughout nature in structural biological materials such as the nacre of abalone [51-53], the spicules of some sea sponges [54,55] and the lamella of cortical bone [56]. The controlled, intrinsic templating of freeze casting through the use of hydrophobic hydration and clathrate hydrates allows for the creation of similar bioinspired designs. Mechanically, these layered structures are known to provide additional toughness through the deflection and blunting of cracks along with other toughening mechanisms ahead of the crack and in its wake [15]. The mechanical analysis presented here on bioinspired freeze cast composites suggests an additional mechanical advantage of these structures as the compliant phases are capable of providing buckling resistance of brittle plates and lamellae.

\section{CONCLUSIONS}

The current experimental study of epoxy-infiltrated, freeze cast $\mathrm{ZrO}_{2}$ bioinspired composites with ethanol $(\mathrm{EtOH}), n$-propanol $(n-\mathrm{PrOH})$ and $n$-butanol $(n-\mathrm{BuOH})$ as additives for intrinsic control enables the following conclusions:

- The addition of $\mathrm{EtOH}, n-\mathrm{PrOH}$ and $n-\mathrm{BuOH}$ all result in an increase in microstructural pore size up to a peak pore area (peak $A_{\mathrm{p}}$ ), which occurs at $10,5-7$ and 3 vol.\% respectively, then a subsequent decrease with increasing concentration. The peak $A_{\mathrm{p}}$ magnitude was largest when $n-\mathrm{PrOH}$ was employed as the additive and, in this case, occurred at the same concentration as previous reports on the use of isopropanol in the freeze casting process.

- Differential scanning calorimetry experiments designed to mimic the freeze casting process suggested that clathrate hydrates were present in $n-\mathrm{PrOH}-\mathrm{H}_{2} \mathrm{O}$ binary mixtures, but not in those involving $\mathrm{EtOH}$ or $n-\mathrm{BuOH}$.

- Sound velocity experiments to determine the compressibility of the slurries examined in this study showed that hydrophobic hydration occurred in all cases. The effects of 
hydrophobic hydration were also shown to be greatest at the same additive concentrations where the peak $A_{\mathrm{p}}$ occurred for each additive. Additionally, experiments on the effect of the solid loading showed that slurry's solid loading particles cause the effect of hydrophobic hydration to be inverted.

- The current study highlights that, when considering the freeze casting process, the effect of hydrophobic hydration at room temperature prior to freezing must be considered, in addition to the low temperature and freezing states.

- Mechanical properties (ultimate compressive strength and modulus) of all two-phase, bioinspired $\mathrm{ZrO}_{2}$-epoxy composites showed an increase in the cases of $n$ - $\mathrm{PrOH}$ and $n$ $\mathrm{BuOH}$ additives, but little change in the case of EtOH. Analysis of the mechanics demonstrated that the composites are incapable of failing in pure compression as would be described by the rule of mixtures due to the preferential Euler buckling mode of the $\mathrm{ZrO}_{2}$ phase. However, the presence of the epoxy provided a large resistance, which was estimated to force the structures to fail in bending modes of $n=18,15$ and 19 for EtOH, $n$ - $\mathrm{PrOH}$ and $n-\mathrm{BuOH}$ respectively.

- The current analysis suggests that layered structural design elements, found throughout nature, may be harnessing this resistance to Euler buckling in order to provide additional strength.

\section{ACKNOWLEDGEMENTS}

This work is supported by a Multi-University Research Initiative through the Air Force Office of Scientific Research (AFOSR-FA9550-15-1-0009). The authors wish to thank Professor Antoi P. Tomsia of Lawrence Berkeley National Laboratory for his guidance on the freeze casting process and Professor Andrzej Burakowski of the University of Wroclaw for his helpful discussion on hydrophobic hydration. 


\section{REFERENCES}

[1] Munch E, Launey ME, Alsem DH, Saiz E, Tomsia AP, Ritchie RO. Tough, bio-inspired hybrid materials. Science 2008;322:1516-20.

[2] Munch E, Saiz E, Tomsia AP, Deville S. Architectural control of freeze-cast ceramics through additives and templating. Journal of the American Ceramic Society 2009;92:1534-9.

[3] Deville S, Saiz E, Nalla RK, Tomsia AP. Freezing as a path to build complex composites. Science 2006;311:515-8.

[4] Deville S, Saiz E, Tomsia AP. Ice-templated porous alumina structures. Acta Materialia 2007;55:1965-74.

[5] Porter MM, McKittrick J, Meyers MA. Biomimetic materials by freeze casting. JOM 2013;65:720-7.

[6] Binner J, Chang H, Higginson R. Processing of ceramic-metal interpenetrating composites. Journal of the European Ceramic Society 2009;29:837-42.

[7] Chen HM, Yin YF, Dong HB, Tong Y, Luo M, Li X. Porous alumina infiltrated with melt and its dynamic analysis during pressureless infiltration. Ceramics International 2014;40:6293-9.

[8] Rao BS, Jayaram $\mathrm{V}$. New technique for pressureless infiltration of $\mathrm{Al}$ alloys into $\mathrm{Al}_{2} \mathrm{O}_{3}$ preforms. Journal of Materials Research 2001;16:2906-13.

[9] Wegst UGK, Bai H, Saiz E, Tomsia AP, Ritchie RO. Bioinspired structural materials Nature Materials 2015;14:23-36.

[10] Wegst UGK, Schecter M, Donius AE, Hunger PM. Biomaterials by freeze casting. Philosophical Transactions of the Royal Society A 2010;368:2099-121. 
[11] Xia ZM, Yu XH, Jiang X, Brody HD, Rowe DW, Wei M. Fabrication and characterization of biomimetic collagen-apatite scaffolds with tunable structures for bone tissue engineering. Acta Biomaterialia 2013;9:7308-19.

[12] Deville S, Saiz E, Tomsia AP. Freeze casting of hydroxyapatite scaffolds for bone tissue engineering. Biomaterials 2006;27:5480-9.

[13] Bai H, Wang D, Delattre B, Gao WW, De Coninck J, Li S, Tomsia AP. Biomimetic gradient scaffold from ice-templating for self-seeding of cells with capillary effect. Acta Biomaterialia 2015;20:113-9.

[14] Bai H, Walsh F, Gludovatz B, Delattre B, Huang C, Chen Y, Tomsia AP, Ritchie RO. Bioinspired hydroxyapatite/poly(methyl methacrylate) composite with a nacre-mimetic architecture by a bidirectional freezing method. Advanced Materials 2015:in press.

[15] Naleway SE, Porter MM, McKittrick J, Meyers MA. Structural design elements in biological materials: Application to bioinspiration. Advanced Materials 2015;27:5455-76.

[16] Olszta MJ, Cheng XG, Jee SS, Kumar R, Kim YY, Kaufman MJ, Douglas EP, Gower LB. Bone structure and formation: A new perspective. Materials Science and Engineering R 2007;58:77-116.

[17] Naleway SE, Taylor JRA, Porter MM, Meyers MA, McKittrick J. Structure and mechanical properties of selected protective systems in marine organisms. Materials Science and Engineering C 2016;59:1143-67.

[18] Ritchie RO. Mechanisms of fatigue-crack propagation in ductile and brittle solids. International Journal of Fracture 1999;100:55-83. 
[19] Porter MM, Imperio R, Wen M, Meyers MA, McKittrick J. Bioinspired scaffolds with varying pore architectures and mechanical properties. Advanced Functional Materials $2013 ; 24: 1978-87$.

[20] Naleway SE, Yu CF, Porter MM, Sengupta A, Iovine PM, Meyers MA, McKittrick J. Bioinspired composites from freeze casting with clathrate hydrates. Materials \& Design 2015;71:62-7.

[21] van der Waals JH, Platteeuw JC. Clathrate Solutions. Advances in Chemical Physics $1959 ; 2: 1-57$.

[22] Ott JB, Goates JR, Waite BA. (Solid + liquid) phase-equilibria and solid-hydrate formation in water + methyl, + ethyl, + isopropyl, and + tertiary butyl alcohols. Journal of Chemical Thermodynamics 1979;11:739-46.

[23] Murthy SSN. Detailed study of ice clathrate relaxation: Evidence for the existence of clathrate structures in some water-alcohol mixtures. Journal of Physical Chemistry A $1999 ; 103: 7927-37$.

[24] Manakov AY, Aladko LS, Ogienko AG, Ancharov AI. Hydrate formation in the system n-propanol-water. Journal of Thermal Analysis and Calorimetry 2013;111:885-90.

[25] Porter MM, Yeh M, Strawson J, Goehring T, Lujan S, Siripasopsotorn P, Meyers MA, McKittrick J. Magnetic freeze casting inspred by nature. Materials Science and Engineering A 2012;556:741-50.

[26] Naleway SE, Fickas KC, Maker YN, Meyers MA, McKittrick J. Reproducibility of $\mathrm{ZrO}_{2^{-}}$ based freeze casting for biomaterials. Materials Science and Engineering C 2016;61:10512. 
[27] Aladko LS, Mankov AY, Ogienko AG, Ancharov AI. New data on phase diagram and clathrate formation in the system water-isopropyl alcohol. Journal of Inclusion Phenomena and Macrocyclic Chemistry 2009;63:151-7.

[28] Takaizumi K. Liquid-solid phase diagrams of $\mathrm{PrOH}-$ water and $\mathrm{BuOH}$-water systems from differential scanning calorimetry. Journal of Solution Chemistry 2000;29:377-88.

[29] Burakowski A, Glinski J. Additivity of adiabatic compressibility with the size and geometry of the solute molecule. Journal of Molecular Liquids 2008;137:25-30.

[30] Jerie K, Baranowski A, Rozenfeld B, Glinski J, Ernst S. Positron-annihilation in and compressibility of water alcohol mixtures. Physica Scripta 1987;35:729-34.

[31] Glinski J, Burakowski A. Compressibility of aqueous solutions of nonelectrolytes: An equilibrium model. Journal of Chemical Physics 2010;132:124507.

[32] Chapoy A, Anderson R, Haghighi H, Edwards T, Tohidi B. Can n-propanol form hydrate? Industrial \& Engineering Chemistry Research 2008;47:1689-94.

[33] Franks F, Desnoyers JE. Alcohol-water mixtures revisited. Water Science Reviews $1985 ; 1: 171-232$.

[34] Galamba N. Water's structure around hydrophobic solutes and the iceberg model. Journal of Physical Chemistry B 2013;117:2153-9.

[35] Burakowski A, Glinski J. Hydration numbers of non-electrolytes - Application of the acoustic method of Pasynski. Chemical Physics 2007;332:336-40.

[36] Bowron DT, Filipponi A, Roberts MA, Finney JL. Hydrophobic hydration and the formation of a clathrate hydrate. Physical Review Letters 1998;81:4164-7.

[37] Burakowski A, Glinski J. Hydration numbers of nonelectrolytes from acoustic methods. Chemical Reviews 2012;112:2059-81. 
[38] Glinski J, Burakowski A. Modification of the Pasynski method for determining the hydration numbers of nonelectrolytes. Chemical Physics Letters 2013;566:21-4.

[39] Glinski J, Burakowski A. Hydration constants of simple non-electrolytes in aqueous solutions determined by the acoustic method. Chemical Physics Letters 2014;614:49-52.

[40] Glinski J, Burakowski A. New interpretation of the concentration dependence of the compressibility of aqueous solutions of nonelectrolytes. International Journal of Thermophysics 2011;32:786-94.

[41] Urick RJ. A sound velocity method for determining the compressibility of finely divided substances. Journal of Applied Physics 1947;18:983-7.

[42] Horváth-Szabóa G, Høiland H. Compressibility determination of silica particles by ultrasound velocity and density measurements on their suspensions. Journal of Colloid and Interface Science 1996;177:568-78.

[43] Caravaca MA, Mino JC, Perez VJ, Casali RA, Ponce CA. Ab initio study of the elastic properties of single and polycrystal $\mathrm{TiO}_{2}, \mathrm{ZrO}_{2}$ and $\mathrm{HfO}_{2}$ in the cotunnite structure. Journal of Physics: Condensed Matter 2009;21:015501.

[44] Molina-Bolivar JA, Ortega-Vinuesa JL. How proteins stabilize colloidal particles by means of hydration forces. Langmuir 1999;15:2644-53.

[45] Sherman NE. Ultrasonic velocity and attenuation in aqueous kaolin dispersions. Journal of Colloid and Interface Science 1991;146:405-14.

[46] Ping ZH, Nguyen QT, Chen SM, Zhou JQ, Ding YD. States of water in different hydrophilic polymers - DSC and FTIR studies. Polymer 2001;42:8461-7.

[47] Gibson LJ, Ashby MF. Cellular Solids: Structure and Properties: Cambridge University Press; 1999. 
[48] Presser V, Schultheiss S, Berthold C, Nickel KG. Sea urchin spines as a model-system for permeable, light-weight ceramics with graceful failure behavior. Part I. Mechanical behavior of sea urchin spines under compression. Journal of Bionic Engineering 2009;6:203-13.

[49] Piconi C, Maccauro G. Zirconia as a ceramic biomaterial Biomaterials 1999;20:1-25.

[50] Boresi AP, Schmidt RJ. Advanced Mechanics of Materials. 6 ed. Hoboken, NJ: Wiley; 2003.

[51] Barthelat F, Tang H, Zavattieri PD, Li CM, Espinosa HD. On the mechanics of motherof-pearl: A key feature in the material hierarchical structure. Journal of the Mechanics and Physics of Solids 2007;55:306-37.

[52] Menig R, Meyers MH, Meyers MA, Vecchio KS. Quasi-static and dynamic mechanical response of Haliotis rufescens (abalone) shells Acta Materialia 2000;48:2383-93.

[53] Barthelat F, Espinosa HD. An experimental investigation of deformation and fracture of nacre-mother of pearl. Experimental Mechanics 2007;47:311-24.

[54] Aizenberg J, Weaver JC, Thanawala MS, Sundar VC, Morse DE, Fratzl P. Skeleton of Euplectella sp.: Structural hierarchy from the nanoscale to the macroscale. Science 2005;309:275-8.

[55] Woesz A, Weaver JC, Kazanci M, Dauphin Y, Aizenberg J, Morse DE, Fratzl P. Micromechanical properties of biological silica in skeletons of deep-sea sponges. Journal of Materials Research 2006;21:2068-78.

[56] Weiner S, Traub W, Wagner HD. Lamellar bone: Structure-function relations. Journal of Structural Biology 1999;126:241-55. 
[57] Zelenin YM. Effect of pressure on clathrate formation in a water-ethanol system. Journal of Structural Chemistry 2003;44:130-6. 


\section{LIST OF TABLE CAPTIONS}

Table 1. Structural and mechanical properties for bioinspired composite scaffolds fabricated with ethanol $(\mathrm{EtOH})$ as an additive. Pore major axis $=a$, pore minor axis $=b$, pore area $=A_{\mathrm{p}}$, pore aspect ratio $=X_{\mathrm{p}}$, wall thickness $=T_{\mathrm{w}}$, composite ceramic volume fraction $=V_{\mathrm{c}}$, ultimate compressive strength $=U C S$, compressive modulus $=E$. Values at the peak $A_{\mathrm{p}}(10 \mathrm{vol} . \%)$ are in bold.

Table 2. Structural and mechanical properties for bioinspired composite scaffolds fabricated with $n$-propanol $(n-\mathrm{PrOH})$ as an additive. Pore major axis $=a$, pore minor axis $=b$, pore area $=$ $A_{\mathrm{p}}$, pore aspect ratio $=X_{\mathrm{p}}$, wall thickness $=T_{\mathrm{w}}$, composite ceramic volume fraction $=V_{\mathrm{c}}$, ultimate compressive strength $=U C S$, compressive modulus $=E$. Values at the peak $A_{\mathrm{p}}(5-7 \mathrm{vol} . \%)$ are in bold.

Table 3. Structural and mechanical properties for bioinspired composite scaffolds fabricated with $n$-butanol $(n-\mathrm{BuOH})$ as an additive. Pore major axis $=a$, pore minor axis $=b$, pore area $=$ $A_{\mathrm{p}}$, pore aspect ratio $=X_{\mathrm{p}}$, wall thickness $=T_{\mathrm{w}}$, composite ceramic volume fraction $=V_{\mathrm{c}}$, ultimate compressive strength $=U C S$, compressive modulus $=E$. Values at the peak $A_{\mathrm{p}}(3 \mathrm{vol} . \%)$ are in bold. 


\section{LIST OF FIGURE CAPTIONS}

Fig. 1. Pore area, $A_{\mathrm{p}}$, data for previously reported and current results using isopropanol as a freeze casting additive. Results are normalized to the pore area with no additive, $A_{\mathrm{p} 0}(0$ vol. $\%$ IPA). Solid loading is different in each case: current results use 15 vol. $\% \mathrm{ZrO}_{2}$, Naleway et al. [20] used 10 vol.\% $\mathrm{ZrO}_{2}$ and Porter et al. [19] used 10 vol.\% $\mathrm{TiO}_{2}$. In each case a parabolic relationship between pore area and IPA concentration is shown with a peak $A_{\mathrm{p}}$ at $5-7 \mathrm{vol} \%$ IPA. Data taken from $[19,20]$.

Fig. 2. Pore area and pore minor axis as a function of additive concentration for $\mathrm{EtOH}, n-\mathrm{PrOH}$ and $n-\mathrm{BuOH}$. (a) Pore area shows peak $A_{\mathrm{p}}$ values at 10, 5-7 and 3 vol.\% for $\mathrm{EtOH}, n-\mathrm{PrOH}$ and $n-\mathrm{BuOH}$ respectively (highlighted), with the maximum concentration being inversely proportional to the size of the additive molecule; (b) Pore aspect ratio shows the same relationship to additive concentration, though the magnitude of scaffolds with $n-\mathrm{BuOH}$ is relatively less. Data is presented as the mean \pm one standard deviation of 40 measurements.

Fig. 3. Scanning electron microscopy images of infiltrated $\mathrm{ZrO}_{2}$ scaffolds. Scaffolds with EtOH, $n$-PrOH and $n-\mathrm{BuOH}$ are shown. In all cases, micrographs are shown for 0,1 and 15 vol.\% additive along with the additive concentration at the peak $A_{\mathrm{p}}$. Ceramic is shown in light grey, polymer in dark grey. Scale bars: $100 \mu \mathrm{m}$.

Fig. 4. Differential scanning calorimetry data for varying concentrations of binary mixtures of EtOH, $n$ - $\mathrm{PrOH}$ and $n-\mathrm{BuOH}$ with water along with associated phase diagrams. (a) EtOH displays only a single endotherm at $\sim 273 \mathrm{~K}$, which from the phase diagram is associated with the decomposition of solid solution ice to a single phase liquid (l); (b) $n$-PrOH displays one additional endotherm at $\sim 263 \mathrm{~K}$ associated with the decomposition of a solid phase, $X$, (proposed to be a hydrate with $n_{\mathrm{h}}=17$ ); (c) $n$ - $\mathrm{BuOH}$ with only a single steep endotherm at $\sim 273 \mathrm{~K}$. Due to the low miscibility of $n-\mathrm{BuOH}$ in water $(\sim 3$ vol.\%), to our knowledge there are no available phase diagrams. Phase diagram data taken from, (a) [57], (b) [24].

Fig. 5. Diagrams of hydrates (from hydrophobic hydration) and clathrate hydrates for an example $n-\mathrm{PrOH}$ molecule. Hydrates $\left(n-\mathrm{PrOH} n_{\mathrm{h}}=3\right)$ form at higher temperatures (e.g. room temperature) while clathrate hydrates $\left(\mathrm{n}-\mathrm{PrOH} n_{\mathrm{h}}=5\right)$ form at low temperatures or high pressures. Both processes cause the solute molecule to template the surrounding $\mathrm{H}_{2} \mathrm{O}$ molecules. 
Fig. 6. The effect of hydrophobic hydration on the adiabatic compressibility coefficient, $k_{\mathrm{S}}$ as a function of additives of monofunctional alcohols (solute). (a) Historical data for $\mathrm{MeOH}, \mathrm{EtOH}$, $n$-PrOH and $n-\mathrm{BuOH}$ displays a parabolic trend with increasing additive. The minimum value of $\kappa_{\mathrm{S}}$ decreases as the size of the additive molecule increases; (b) As $\kappa_{\mathrm{s}}$ decreases towards the minimum, additive molecules are completely dispersed and each forms a hydrate; (c) Past the minimum, the liquid is saturated with hydrates and free solute becomes present. Data for $n$ $\mathrm{BuOH}$ is only available up to the solubility limit of $\sim 3$ vol.\%. Data for $\mathrm{MeOH}, \mathrm{EtOH}$ and $n$ PrOH taken from [31], data for $n$ - $\mathrm{BuOH}$ graciously provided by A. Burakowski.

Fig. 7. The effect of solid loading concentration on adiabatic compressibility (a) At concentrations $<5$ vol. $\% \mathrm{ZrO}_{2}$ particles, the addition of 7 vol. $\% n$-PrOH causes a decrease in $k_{\mathrm{s}}$, which is similar to results on binary mixtures of monofunctional alcohols and $\mathrm{H}_{2} \mathrm{O}$ due to the effects of hydrophobic hydration. At concentrations $>10$ vol. $\% \mathrm{ZrO}_{2}$ particles, the addition of 7 vol.\% $n-\mathrm{PrOH}$ causes a large increase in $\kappa_{\mathrm{s}}$, inverting the response of $\kappa_{\mathrm{s}}$ to hydrophobic hydration; (b) The sound velocity, $c$, of both the base and $n$-PrOH 7 vol.\% samples decrease with increasing solid loading; (c) The density, $\rho$, increases with solid loading in the base sample, but shows a decrease with the $n-\mathrm{PrOH}$ additive at 15 vol. $\%$ solid loading. This is proposed to be the effect of hydrates forming around the solid loading (inset). Data is presented as the mean \pm one standard deviation of five measurements.

Fig. 8. Adiabatic compressibility, $k_{\mathrm{s}}$, as a function of additive concentration for complete slurries. Maxima occur at the concentrations of 10,7 and 5 vol.\% for EtOH, $n$-PrOH and $n$ $\mathrm{BuOH}$ respectively. These maxima occur at the same concentrations as the observed peak $A_{\mathrm{p}}$ values shown in Fig. 2a and are associated with the effects of hydrophobic hydration. Data is presented as the mean \pm one standard deviation of five measurements.

Fig. 9. Diagram of the proposed mechanism connecting hydrophobic hydration to the enlarged porosity in the final freeze cast scaffolds. The presence of the enlarged hydrates, shown on the right compared to pure $\mathrm{H}_{2} \mathrm{O}$ on the left, in the liquid phase ahead of the freezing front results in enlarged ice crystals, which in turn result in larger porosity.

Fig. 10. (a) Normalized ultimate compressive strength (divided by $U C S_{0}$, the ultimate compressive strength of a scaffold with 0 vol.\% additive) and (b) normalized compressive modulus (divided by $E_{0}$, the modulus of a scaffold with 0 vol.\% additive) data as a function of 
additive concentration for $\mathrm{EtOH}, n-\mathrm{PrOH}$ and $n-\mathrm{BuOH}$. In order to focus on the trends in mechanical properties, the values are all normalized. In both cases, EtOH shows little change regardless of additive concentration, $n$ - $\mathrm{PrOH}$ reaches a maximum at 3-5 vol. $\%$ and $n$ - $\mathrm{BuOH}$ reaches a maximum at $3 \mathrm{vol} . \%$. Note that the magnitude of both $U C S$ and $E$ is greatest in the case of $n$-PrOH. Data is presented as the mean \pm one standard deviation of five measurements.

Fig. 11. Representative stress-strain curves from each of the peak $A_{\mathrm{p}}$ samples. It can be seen in all cases that initial failure occurs with little plasticity. However, the samples are still capable of maintaining a significant amount of stress after failure, thus increasing the toughness of the material.

Fig. 12. Mechanical property analysis of the current bioinspired composites. (a) A simplified two-phase (polymer in pink and $\mathrm{ZrO}_{2}$ ceramic in yellow) layered composite model is considered using the experimentally measured geometric dimensions of $w, l$ and $T_{\mathrm{w}}$. The strength is considered to be a function of axial compression of the polymer phase and supported Euler buckling of the $\mathrm{ZrO}_{2}$ ceramic; (b) While the current bioinspired composites are unable to provide rigid support (as would be predicted by the rule of mixtures), they do provide significant buckling resistance, which is estimated to result in a buckling mode of $n=15-19$. This is orders of magnitude higher than the calculated strength of uninfiltrated, or unsupported, scaffolds $(n=$ $1)$. 


\section{TABLES}

Table 1. Structural and mechanical properties for bioinspired composite scaffolds fabricated with ethanol $(\mathrm{EtOH})$ as an additive. Pore major axis $=a$, pore minor axis $=b$, pore area $=A_{\mathrm{p}}$, pore aspect ratio $=X_{\mathrm{p}}$, wall thickness $=T_{\mathrm{w}}$, composite ceramic volume fraction $=V_{\mathrm{c}}$, ultimate compressive strength $=U C S$, compressive modulus $=E$. Values at the peak $A_{\mathrm{p}}(10 \mathrm{vol} . \%)$ are in bold.

\begin{tabular}{|c|c|c|c|c|c|c|c|c|}
\hline $\begin{array}{c}\text { EtOH } \\
\text { (vol.\%) }\end{array}$ & $\begin{array}{c}a \\
(\mu \mathrm{m})\end{array}$ & $\begin{array}{c}b \\
(\mu \mathrm{m})\end{array}$ & $\begin{array}{c}A_{\mathrm{p}} \\
\left(\mu \mathrm{m}^{2}\right)\end{array}$ & $X_{p}$ & $\begin{array}{c}T_{\mathrm{w}} \\
(\mu \mathrm{m})\end{array}$ & $V_{c}$ & $\begin{array}{c}U C S \\
(\mathrm{MPa})\end{array}$ & $\begin{array}{c}E \\
(\mathrm{GPa}) \\
\end{array}$ \\
\hline 0 & $\begin{array}{l}59.6 \pm \\
26.4\end{array}$ & $15.4 \pm 3.7$ & $752 \pm 474$ & $3.9 \pm 1.6$ & $6.3 \pm 2.0$ & $\begin{array}{l}0.27 \pm \\
0.01\end{array}$ & $138 \pm 17$ & $3.8 \pm 0.7$ \\
\hline 1 & $\begin{array}{l}127.6 \pm \\
46.6\end{array}$ & $21.2 \pm 6.0$ & $\begin{array}{l}2263 \pm \\
1418\end{array}$ & $6.1 \pm 1.7$ & $11.0 \pm 4.0$ & $\begin{array}{l}0.27 \pm \\
0.01\end{array}$ & $160 \pm 14$ & $4.4 \pm 1.0$ \\
\hline 3 & $\begin{array}{l}130.1 \pm \\
53.6\end{array}$ & $23.5 \pm 5.4$ & $\begin{array}{l}2518 \pm \\
1536\end{array}$ & $5.6 \pm 1.9$ & $10.7 \pm 3.3$ & $\begin{array}{l}0.27 \pm \\
0.01\end{array}$ & $155 \pm 29$ & $4.3 \pm 1.7$ \\
\hline 5 & $\begin{array}{l}163.0 \pm \\
66.8\end{array}$ & $26.2 \pm 5.9$ & $\begin{array}{l}3510 \pm \\
1867\end{array}$ & $6.3 \pm 2.2$ & $13.3 \pm 4.0$ & $\begin{array}{l}0.28 \pm \\
0.01\end{array}$ & $131 \pm 14$ & $3.6 \pm 0.8$ \\
\hline 7 & $\begin{array}{l}174.6 \pm \\
73.7\end{array}$ & $24.1 \pm 5.2$ & $\begin{array}{l}3406 \pm \\
1788\end{array}$ & $7.3 \pm 2.9$ & $13.9 \pm 4.2$ & $\begin{array}{l}0.29 \pm \\
0.02\end{array}$ & $125 \pm 6$ & $2.7 \pm 0.7$ \\
\hline 10 & $\begin{array}{l}258.6 \pm \\
87.2\end{array}$ & $27.9 \pm 6.1$ & $\begin{array}{l}5964 \pm \\
3006\end{array}$ & $9.2 \pm 2.3$ & $17.6 \pm 4.3$ & $\begin{array}{l}0.31 \pm \\
0.03\end{array}$ & $147 \pm 10$ & $4.5 \pm 0.6$ \\
\hline 15 & $\begin{array}{l}72.0 \pm \\
20.2\end{array}$ & $11.8 \pm 2.1$ & $673 \pm 249$ & $6.3 \pm 1.9$ & $12.9 \pm 4.1$ & $\begin{array}{l}0.33 \pm \\
0.01\end{array}$ & $136 \pm 5$ & $3.2 \pm 0.6$ \\
\hline
\end{tabular}

All data is presented as the mean \pm standard deviation 
Table 2. Structural and mechanical properties for bioinspired composite scaffolds fabricated with $n$-propanol $(n$-PrOH $)$ as an additive. Pore major axis $=a$, pore minor axis $=b$, pore area $=$ $A_{\mathrm{p}}$, pore aspect ratio $=X_{\mathrm{p}}$, wall thickness $=T_{\mathrm{w}}$, composite ceramic volume fraction $=V_{\mathrm{c}}$, ultimate compressive strength $=U C S$, compressive modulus $=E$. Values at the peak $A_{\mathrm{p}}(5-7$ vol.\%) are in bold.

\begin{tabular}{|c|c|c|c|c|c|c|c|c|}
\hline $\begin{array}{c}n-\mathrm{PrOH} \\
\text { (vol.\%) }\end{array}$ & $\begin{array}{c}a \\
(\mu \mathrm{m})\end{array}$ & $\begin{array}{c}b \\
(\mu \mathrm{m})\end{array}$ & $\begin{array}{c}A_{p} \\
\left(\mu \mathrm{m}^{2}\right)\end{array}$ & $X_{p}$ & $\begin{array}{c}T_{\mathrm{w}} \\
(\mu \mathrm{m})\end{array}$ & $V_{c}$ & $\begin{array}{c}\text { UCS } \\
\text { (MPa) }\end{array}$ & $\begin{array}{c}E \\
(\mathrm{GPa})\end{array}$ \\
\hline \multirow[t]{2}{*}{0} & $50.9 \pm$ & $13.0 \pm$ & $532 \pm$ & $4.0 \pm 1.3$ & $8.2 \pm 2.1$ & $0.26 \pm$ & $90 \pm 35$ & $1.4 \pm 0.5$ \\
\hline & 18.2 & 2.6 & 252 & & & 0.02 & & \\
\hline \multirow[t]{2}{*}{1} & $115.7 \pm$ & $21.2 \pm$ & $2027 \pm$ & $5.4 \pm 1.6$ & $10.0 \pm$ & $0.26 \pm$ & $90 \pm 39$ & $1.9 \pm 1.1$ \\
\hline & 46.2 & 4.4 & 1150 & & 2.2 & 0.05 & & \\
\hline \multirow[t]{2}{*}{3} & $191.0 \pm$ & $28.8 \pm$ & $4534 \pm$ & $6.5 \pm 2.4$ & $12.9 \pm$ & $0.30 \pm$ & $132 \pm 18$ & $3.3 \pm 0.7$ \\
\hline & 92.2 & 4.7 & 2820 & & 4.7 & 0.01 & & \\
\hline \multirow[t]{2}{*}{5} & $365.0 \pm$ & $35.3 \pm$ & $10540 \pm$ & $10.1 \pm 3.7$ & $20.2 \pm$ & $0.29 \pm$ & $131 \pm 17$ & $3.3 \pm 1.0$ \\
\hline & 162.8 & 5.0 & 5662 & & 4.7 & 0.01 & & \\
\hline \multirow[t]{2}{*}{7} & $354.4 \pm$ & $34.3 \pm$ & $10287 \pm$ & $9.9 \pm 3.9$ & $19.8 \pm$ & $0.30 \pm$ & $107 \pm 17$ & $1.9 \pm 0.6$ \\
\hline & 190.6 & 6.9 & 7218 & & 5.4 & 0.02 & & \\
\hline \multirow[t]{2}{*}{10} & $226.4 \pm$ & $26.5 \pm$ & $4969 \pm$ & $8.6 \pm 2.5$ & $13.8 \pm$ & $0.30 \pm$ & $119 \pm 9$ & $2.5 \pm 0.9$ \\
\hline & 85.5 & 6.2 & 2900 & & 4.6 & 0.03 & & \\
\hline \multirow[t]{2}{*}{15} & $147.1 \pm$ & $20.8 \pm$ & $2436 \pm$ & $7.2 \pm 2.5$ & $11.7 \pm$ & $0.30 \pm$ & $124 \pm 9$ & $3.0 \pm 0.6$ \\
\hline & 49.7 & 3.8 & 1004 & & 4.5 & 0.01 & & \\
\hline
\end{tabular}

All data is presented as the mean \pm standard deviation 
Table 3. Structural and mechanical properties for bioinspired composite scaffolds fabricated with $n$-butanol $(n-\mathrm{BuOH})$ as an additive. Pore major axis $=a$, pore minor axis $=b$, pore area $=$ $A_{\mathrm{p}}$, pore aspect ratio $=X_{\mathrm{p}}$, wall thickness $=T_{\mathrm{w}}$, composite ceramic volume fraction $=V_{\mathrm{c}}$, ultimate compressive strength $=U C S$, compressive modulus $=E$. Values at the peak $A_{\mathrm{p}}(3$ vol.\%) are in bold.

\begin{tabular}{|c|c|c|c|c|c|c|c|c|}
\hline $\begin{array}{c}n-\mathrm{BuOH} \\
\text { (vol.\%) }\end{array}$ & $\begin{array}{c}a \\
(\mu \mathrm{m})\end{array}$ & $\begin{array}{c}b \\
(\mu \mathrm{m})\end{array}$ & $\begin{array}{c}A_{\mathrm{p}} \\
\left(\mu \mathrm{m}^{2}\right)\end{array}$ & $X_{p}$ & $\begin{array}{c}T_{\mathrm{w}} \\
(\mu \mathrm{m})\end{array}$ & $V_{c}$ & $\begin{array}{c}\text { UCS } \\
\text { (MPa) }\end{array}$ & $\begin{array}{c}E \\
(\mathrm{GPa})\end{array}$ \\
\hline 0 & $\begin{array}{l}49.3 \pm \\
20.6\end{array}$ & $13.8 \pm 3.5$ & $560 \pm 315$ & $3.6 \pm 1.4$ & $6.8 \pm 2.0$ & $\begin{array}{l}0.28 \pm \\
0.01\end{array}$ & $122 \pm 9$ & $2.0 \pm 0.6$ \\
\hline 1 & $\begin{array}{l}84.7 \pm \\
30.1\end{array}$ & $18.0 \pm 3.4$ & $\begin{array}{l}1211 \pm \\
529\end{array}$ & $4.8 \pm 1.8$ & $10.6 \pm 3.3$ & $\begin{array}{l}0.28 \pm \\
0.01\end{array}$ & $148 \pm 37$ & $3.2 \pm 0.9$ \\
\hline 3 & $\begin{array}{l}232.4 \pm \\
119.6\end{array}$ & $41.3 \pm 7.2$ & $\begin{array}{l}7998 \pm \\
5295\end{array}$ & $5.5 \pm 2.1$ & $20.2 \pm 5.1$ & $\begin{array}{l}0.27 \pm \\
0.01\end{array}$ & $162 \pm 7$ & $4.0 \pm 0.4$ \\
\hline 5 & $\begin{array}{l}80.3 \pm \\
22.3\end{array}$ & $20.6 \pm 3.9$ & $\begin{array}{l}1325 \pm \\
538\end{array}$ & $4.0 \pm 1.2$ & $8.6 \pm 3.0$ & $\begin{array}{l}0.27 \pm \\
0.02\end{array}$ & $103 \pm 30$ & $2.8 \pm 0.9$ \\
\hline 7 & $\begin{array}{l}82.4 \pm \\
28.4\end{array}$ & $20.1 \pm 4.1$ & $\begin{array}{l}1354 \pm \\
652\end{array}$ & $4.1 \pm 1.1$ & $8.9 \pm 3.5$ & $\begin{array}{l}0.28 \pm \\
0.01\end{array}$ & $115 \pm 5$ & $2.1 \pm 0.6$ \\
\hline 10 & $\begin{array}{l}77.3 \pm \\
23.5\end{array}$ & $17.7 \pm 3.0$ & $\begin{array}{l}1099 \pm \\
426\end{array}$ & $4.4 \pm 1.2$ & $10.7 \pm 4.5$ & $\begin{array}{l}0.29 \pm \\
0.02\end{array}$ & $116 \pm 12$ & $2.4 \pm 0.7$ \\
\hline 15 & $\begin{array}{l}137.4 \pm \\
60.8\end{array}$ & $22.3 \pm 6.8$ & $\begin{array}{l}2645 \pm \\
2161\end{array}$ & $6.2 \pm 2.0$ & $14.1 \pm 5.2$ & $\begin{array}{l}0.28 \pm \\
0.01\end{array}$ & $123 \pm 12$ & $2.1 \pm 0.7$ \\
\hline
\end{tabular}

All data is presented as the mean \pm standard deviation 


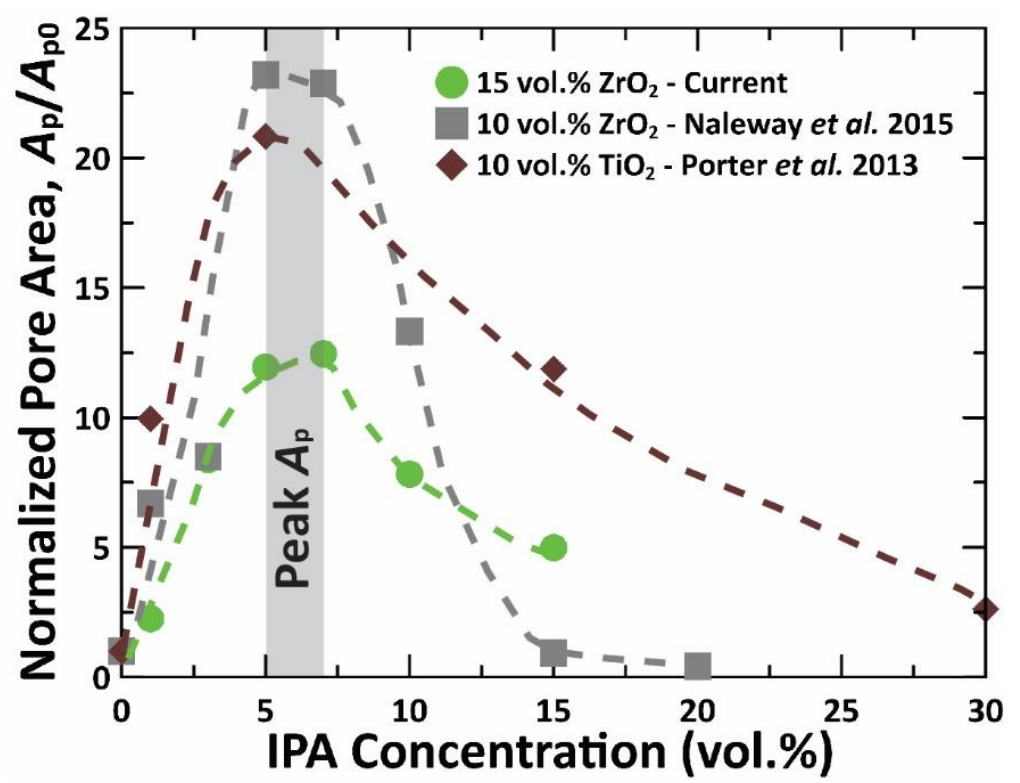

Fig. 1. Pore area, $A_{\mathrm{p}}$, data for previously reported and current results using isopropanol as a freeze casting additive. Results are normalized to the pore area with no additive, $A_{\mathrm{p} 0}(0 \mathrm{vol} \%$ IPA). Solid loading is different in each case: current results use $15 \mathrm{vol} . \% \mathrm{ZrO}_{2}$, Naleway et al. [19] used $10 \mathrm{vol} . \% \mathrm{ZrO}_{2}$ and Porter et al. [18] used $10 \mathrm{vol} . \% \mathrm{TiO}_{2}$. In each case a parabolic relationship between pore area and IPA concentration is shown with a peak $A_{\mathrm{p}}$ at 5 - 7 vol.\% IPA. Data taken from $[18,19]$. 

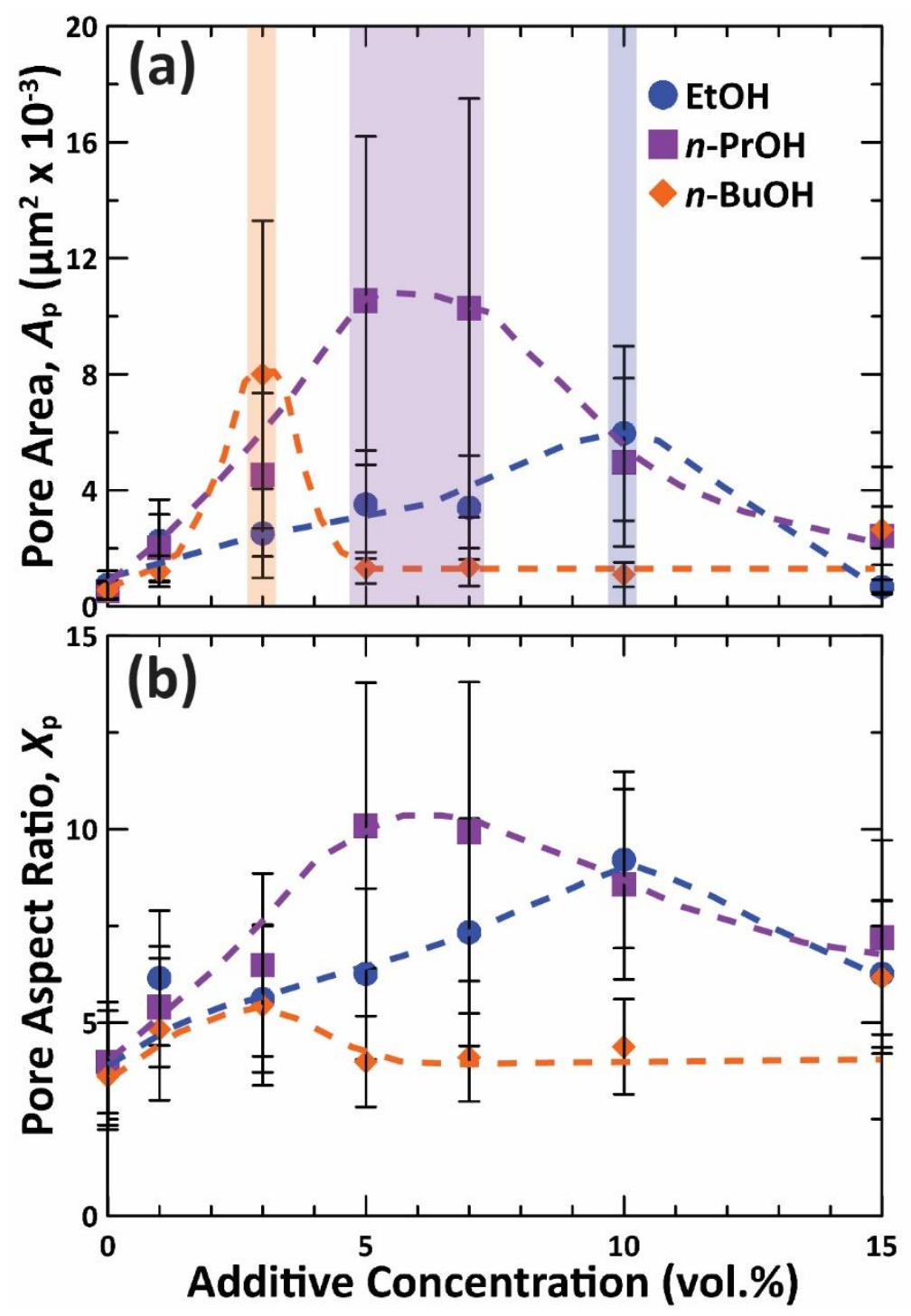

Fig. 2. Pore area and pore minor axis as a function of additive concentration for EtOH, $n$ $\mathrm{PrOH}$ and $n-\mathrm{BuOH}$. (a) Pore area shows peak $A_{\mathrm{p}}$ values at 3, 5-7 and 10 vol.\% for EtOH, $n$ $\mathrm{PrOH}$ and $n-\mathrm{BuOH}$ respectively (highlighted), with the maximum concentration being inversely proportional to the size of the additive molecule; (b) Pore aspect ratio shows the same relationship to additive concentration, though the magnitude of scaffolds with $n$ - $\mathrm{BuOH}$ is relatively less. Data is presented as the mean \pm one standard deviation of 40 measurements. 


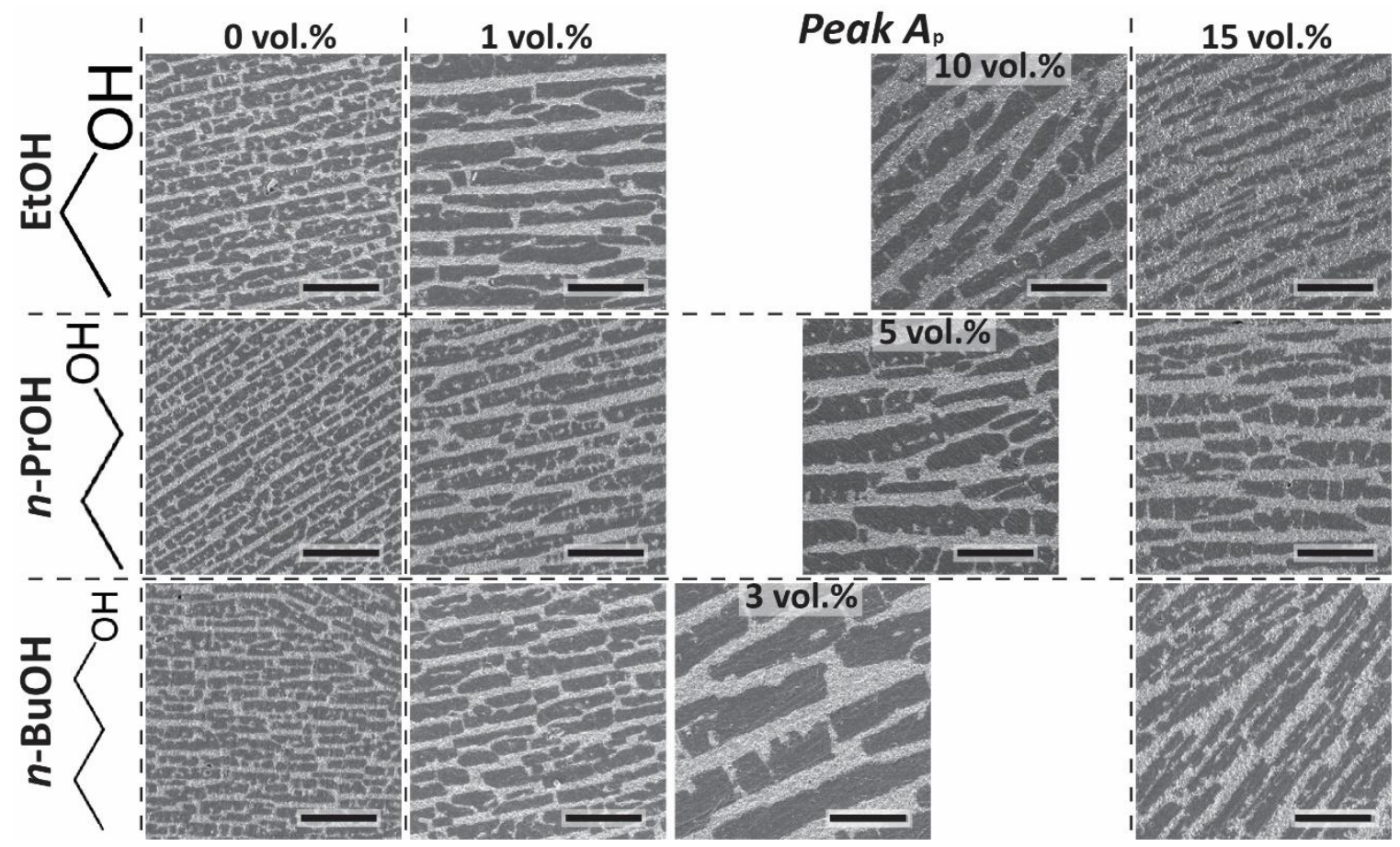

Fig. 3. Scanning electron microscopy images of infiltrated $\mathrm{ZrO}_{2}$ scaffolds. Scaffolds with EtOH, $n$-PrOH and $n$ - $\mathrm{BuOH}$ are shown. In all cases, micrographs are shown for 0,1 and 15 vol.\% additive along with the additive concentration at the peak $A_{\mathrm{p}}$. Ceramic is shown in light grey, polymer in dark grey. Scale bars: $100 \mu \mathrm{m}$. 

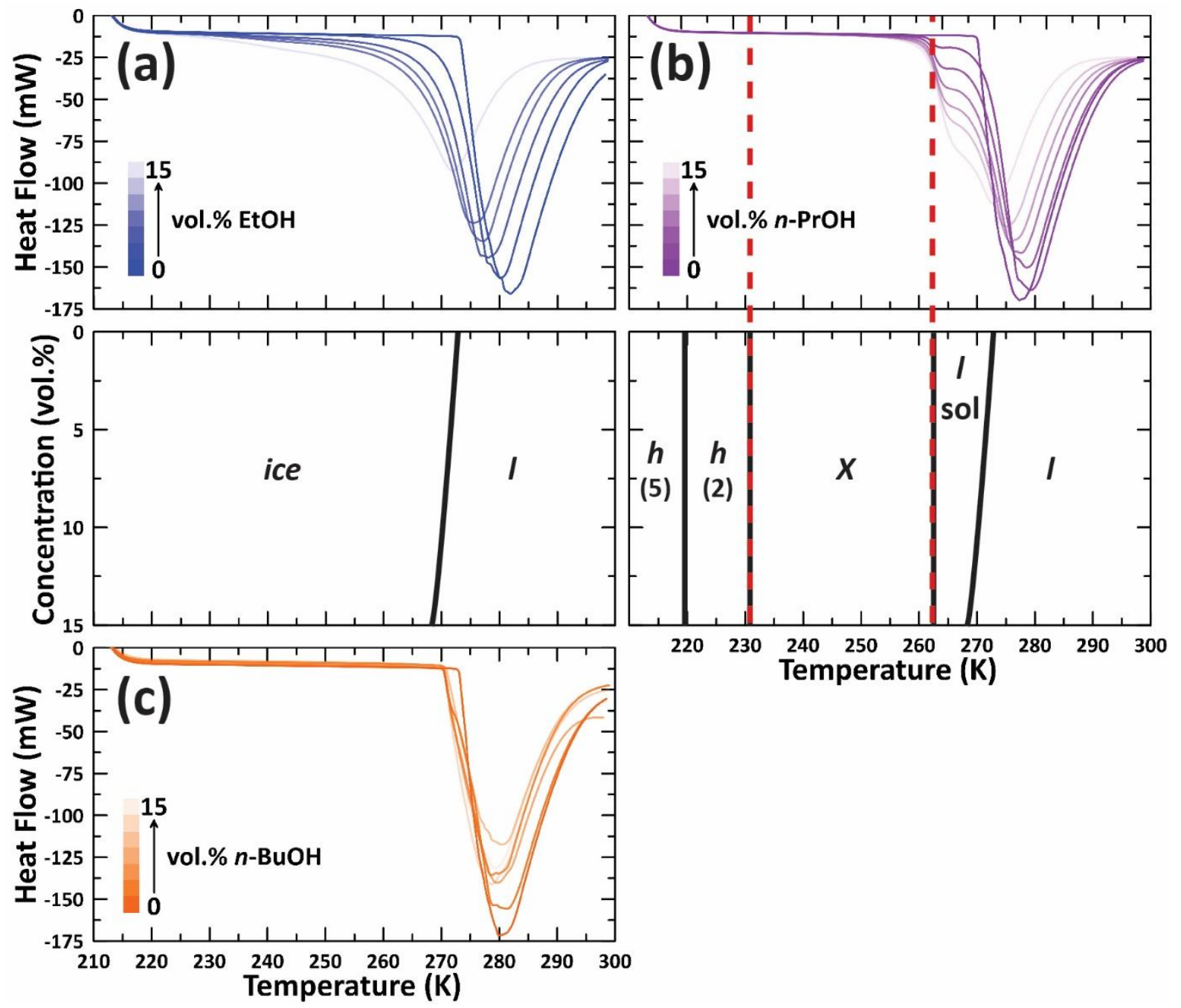

Fig. 4. Differential scanning calorimetry data for varying concentrations of binary mixtures of $\mathrm{EtOH}, n$-PrOH and $n-\mathrm{BuOH}$ with water along with associated phase diagrams. (a) EtOH displays only a single endotherm at $\sim 273 \mathrm{~K}$, which from the phase diagram is associated with the decomposition of solid solution ice to a single phase liquid (l); (b) $n$-PrOH displays one additional endotherm at $\sim 263 \mathrm{~K}$ associated with the decomposition of a solid phase, $X$, (either a hydrate with $n_{\mathrm{h}}=17$ or solid solution ice); (c) $n$ - $\mathrm{BuOH}$ with only a single steep endotherm at $\sim 273 \mathrm{~K}$. Due to the low miscibility of $n-\mathrm{BuOH}$ in water ( 3 vol.\%), to our knowledge there are no available phase diagrams. Phase diagram data taken from, (a) [53], (b) [23]. 


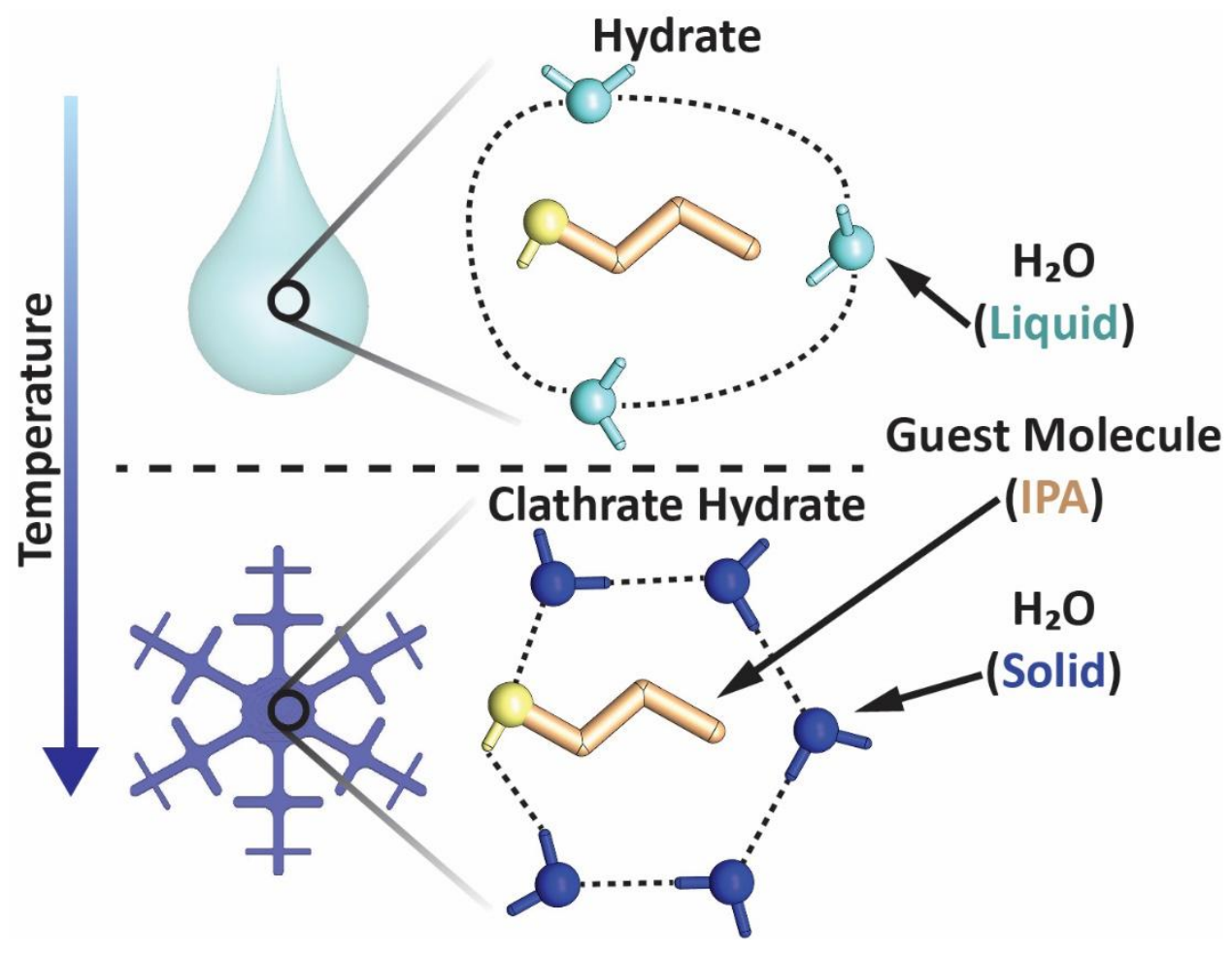

Fig. 5. Diagrams of hydrates (from hydrophobic hydration) and clathrate hydrates for an example $n$-PrOH molecule. Hydrates $\left(n-\mathrm{PrOH} n_{\mathrm{h}}=3\right)$ form at higher temperatures (e.g. room temperature) while clathrate hydrates $\left(\mathrm{n}-\mathrm{PrOH} n_{\mathrm{h}}=5\right)$ form at low temperatures or high pressures. Both processes cause the solute molecule to template the surrounding $\mathrm{H}_{2} \mathrm{O}$ molecules. 

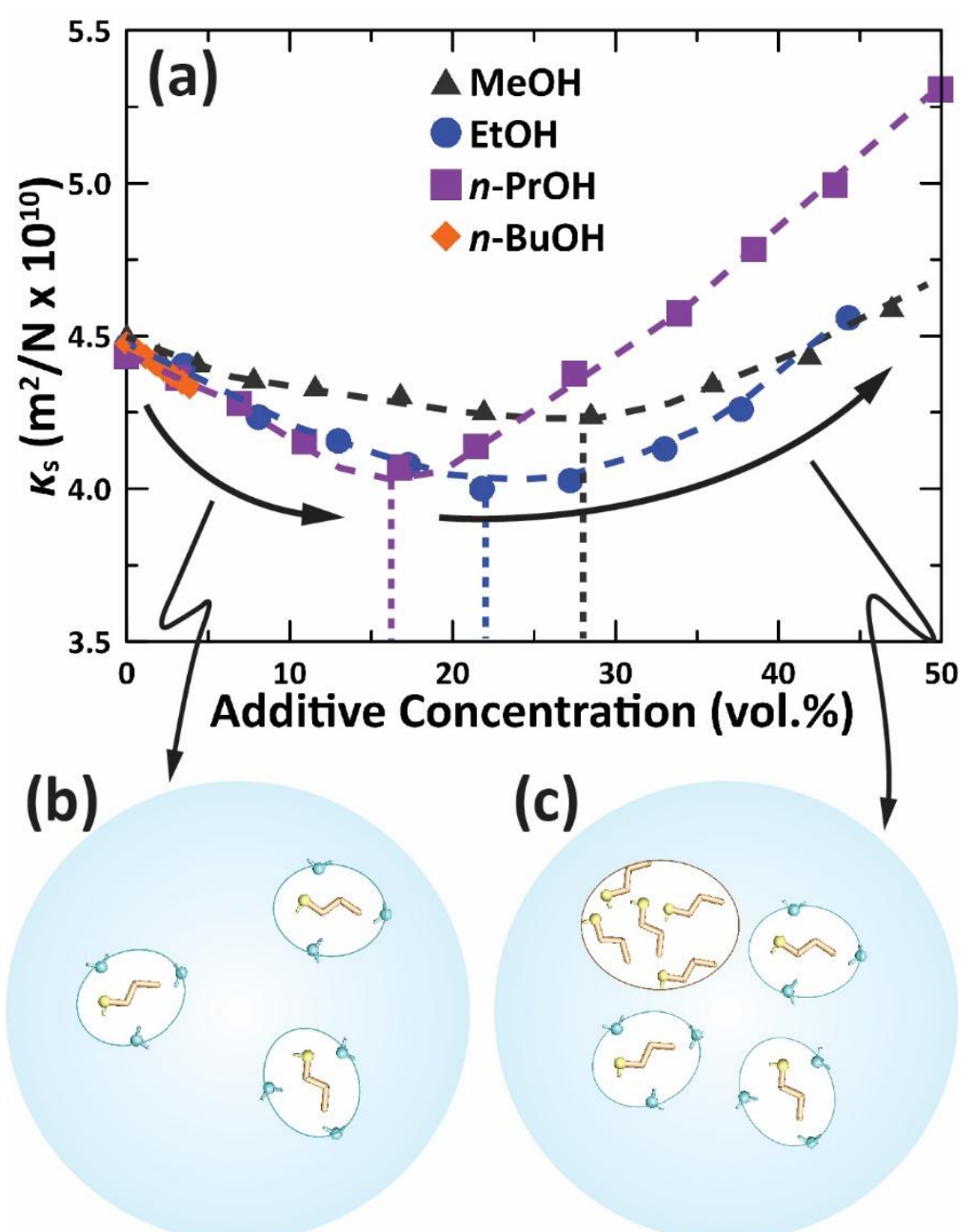

Fig. 6. The effect of hydrophobic hydration on the adiabatic compressibility coefficient, $k_{\mathrm{s}}$ as a function of additives of monofunctional alcohols (solute). (a) Historical data for $\mathrm{MeOH}, \mathrm{EtOH}$, $n$-PrOH and $n-\mathrm{BuOH}$ displays a parabolic trend with increasing additive. The minimum value of $\kappa_{\mathrm{s}}$ decreases as the size of the additive molecule increases; (b) As $\kappa_{\mathrm{s}}$ decreases towards the minimum, additive molecules are completely dispersed and each forms a hydrate; (c) Past the minimum, the liquid is saturated with hydrates and free solute becomes present. Data for $n$ $\mathrm{BuOH}$ is only available up to the solubility limit of $\sim 3 \mathrm{vol} . \%$. Data for $\mathrm{MeOH}, \mathrm{EtOH}$ and $n$ $\mathrm{PrOH}$ taken from [30], data for $n$-BuOH graciously provided by A. Burakowski. 


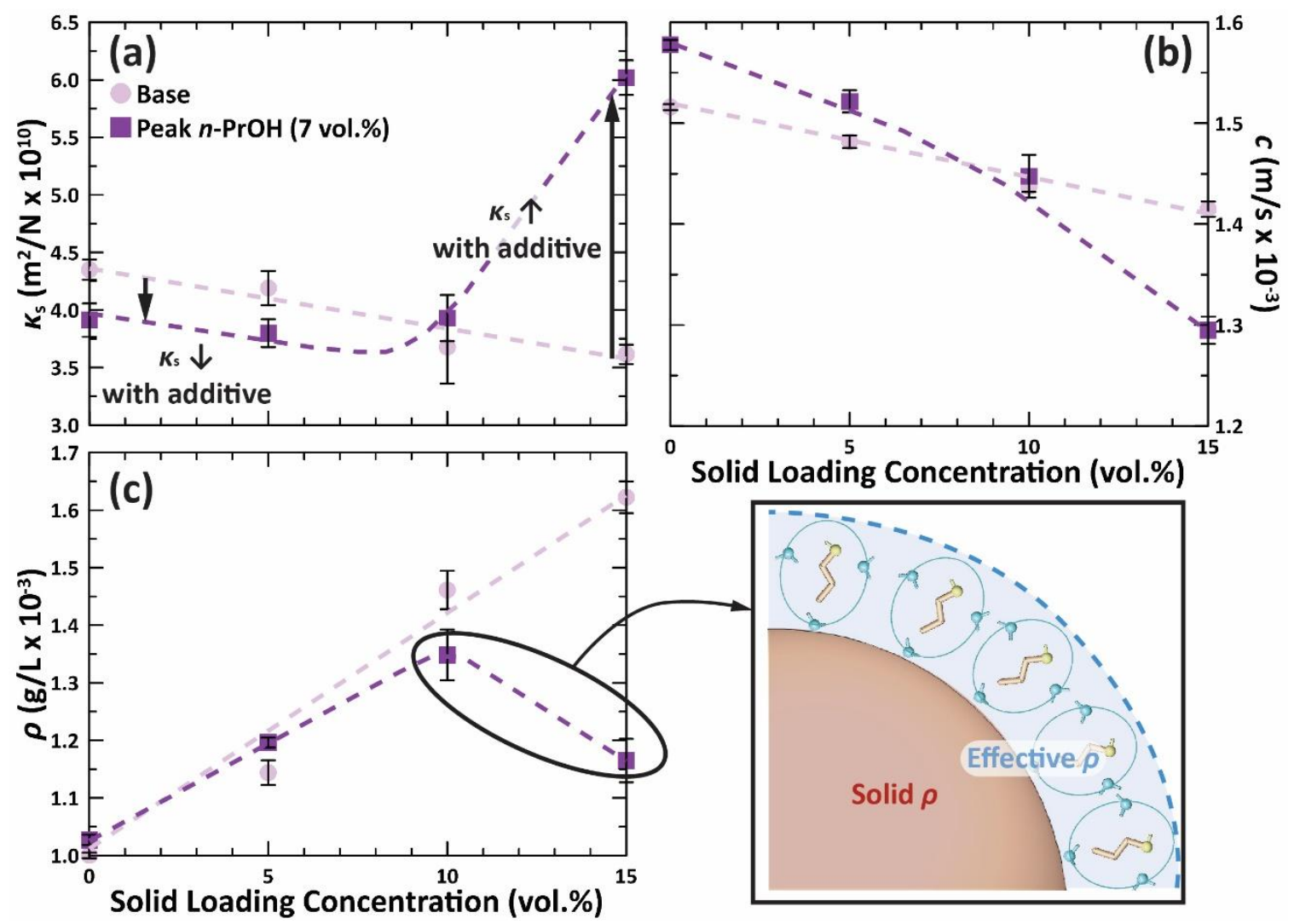

Fig. 7. The effect of solid loading concentration on adiabatic compressibility (a) At concentrations $<5 \mathrm{vol} . \% \mathrm{ZrO}_{2}$ particles, the addition of $7 \mathrm{vol} . \% n-\mathrm{PrOH}$ causes a decrease in $\kappa_{\mathrm{s}}$, which is similar to results on binary mixtures of monofunctional alcohols and $\mathrm{H}_{2} \mathrm{O}$ due to the effects of hydrophobic hydration. At concentrations $>10 \mathrm{vol} . \% \mathrm{ZrO}_{2}$ particles, the addition of 7 vol. $\% n$-PrOH causes a large increase in $k_{\mathrm{s}}$, inverting the response of $k_{\mathrm{s}}$ to hydrophobic hydration; (b) The sound velocity, $c$, of both the base and $n$-PrOH 7 vol.\% samples decrease with increasing solid loading; (c) The density, $\rho$, increases with solid loading in the base sample, but shows a decrease with the $n$-PrOH additive at 15 vol.\% solid loading. This is proposed to be the effect of hydrates forming around the solid loading (inset). Data is presented as the mean \pm one standard deviation of five measurements. 


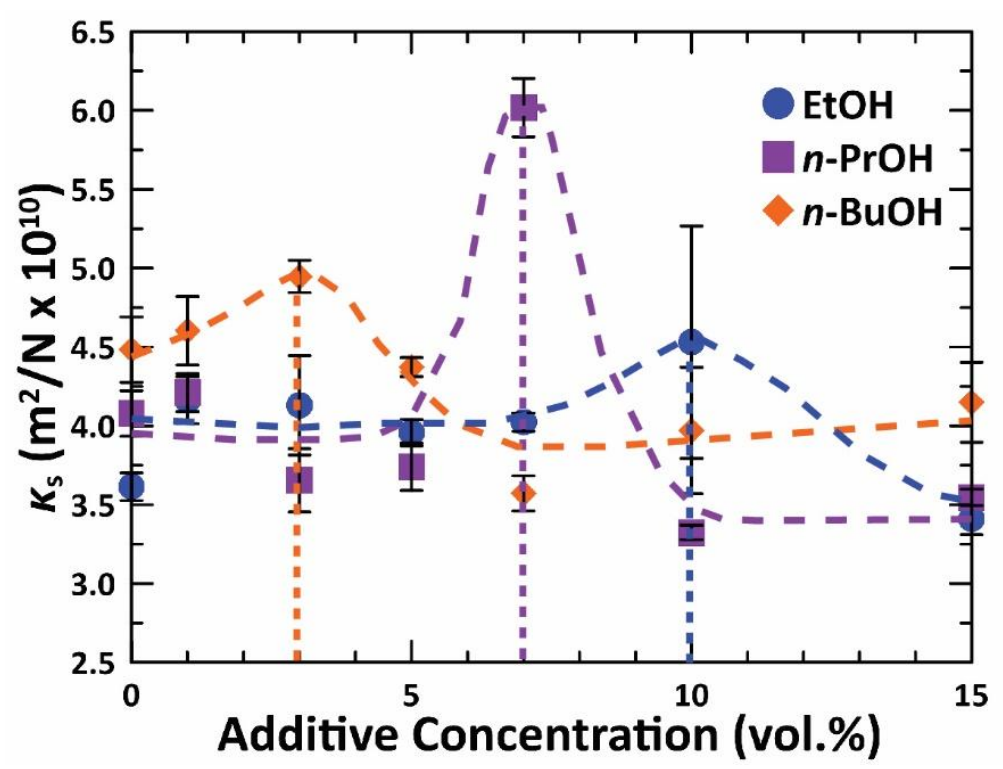

Fig. 8. Adiabatic compressibility, $\kappa_{\mathrm{s}}$, as a function of additive concentration for complete slurries. Maxima occur at the concentrations of 10,7 and 5 vol.\% for EtOH, $n$-PrOH and $n$ $\mathrm{BuOH}$ respectively. These maxima occur at the same concentrations as the observed peak $A_{\mathrm{p}}$ values shown in Fig. 2a and are associated with the effects of hydrophobic hydration. Data is presented as the mean \pm one standard deviation of five measurements. 


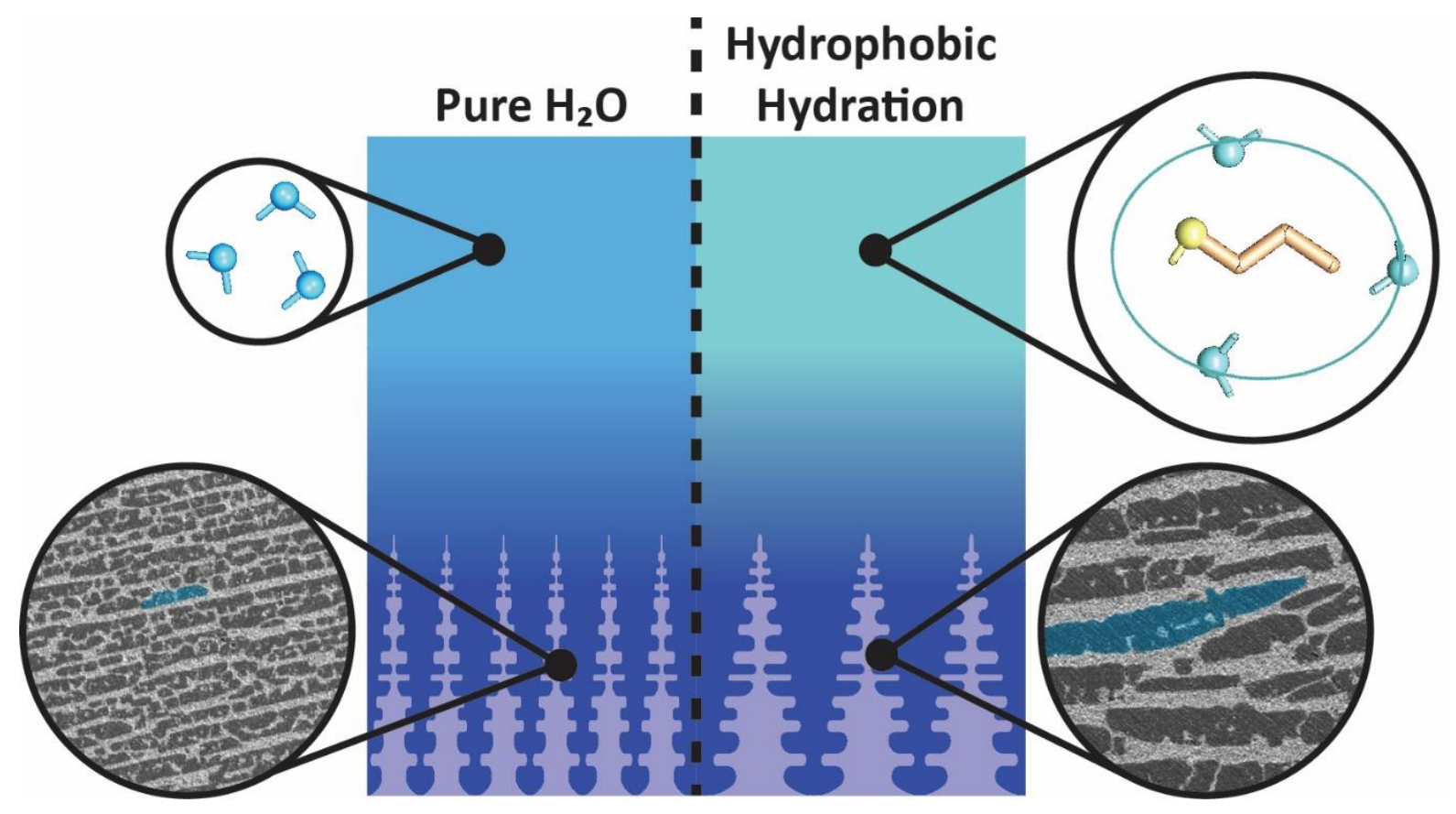

Fig. 9. Diagram of the proposed mechanism connecting hydrophobic hydration to the enlarged porosity in the final freeze cast scaffolds. The presence of the enlarged hydrates in the liquid phase ahead of the freezing front results in enlarged ice crystals, which in turn result in larger porosity. 

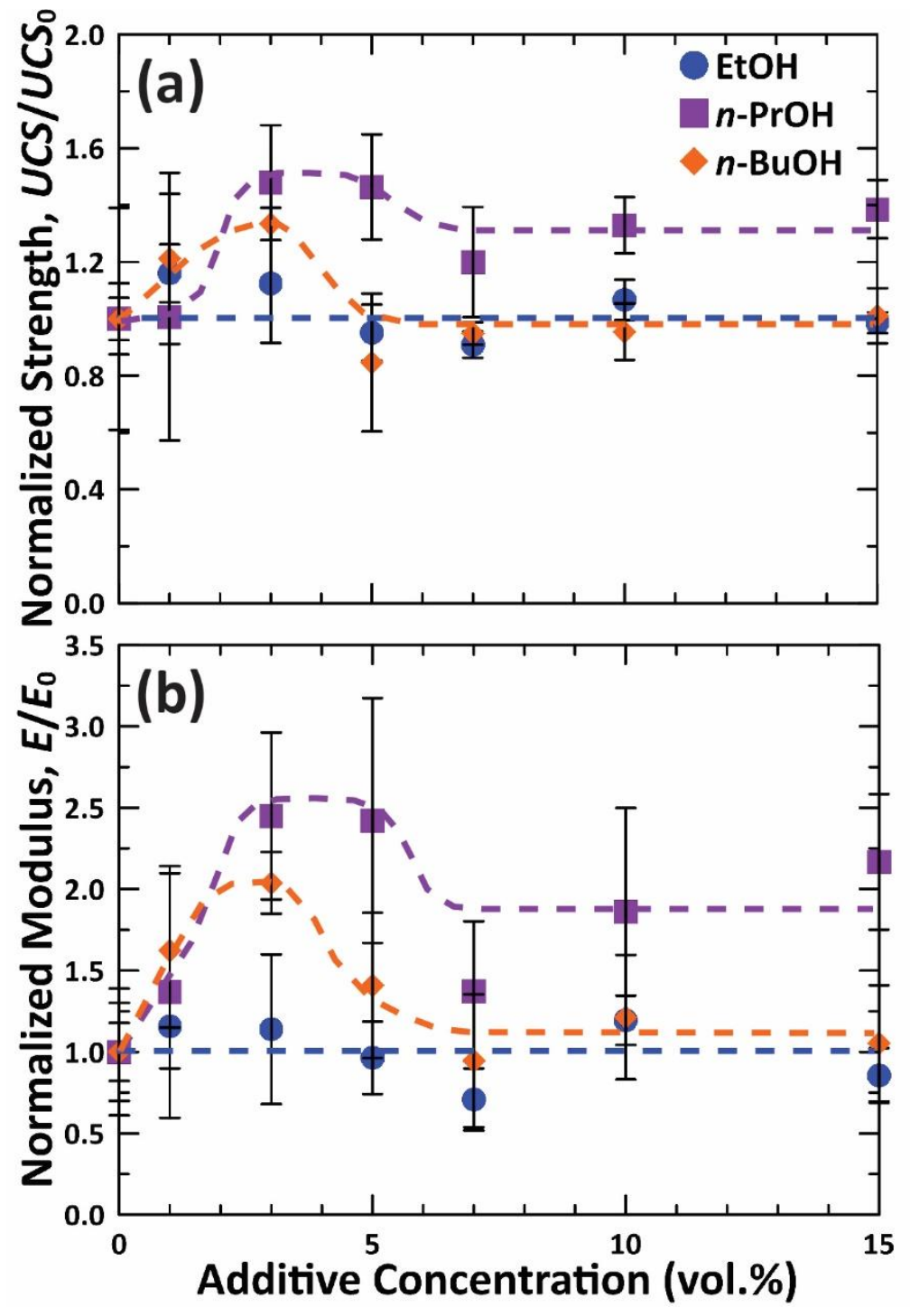

Fig. 10. (a) Normalized ultimate compressive strength (divided by $U C S_{0}$, the ultimate compressive strength of a scaffold with 0 vol.\% additive) and (b) normalized compressive modulus (divided by $E_{0}$, the modulus of a scaffold with 0 vol.\% additive) data as a function of additive concentration for EtOH, $n-\mathrm{PrOH}$ and $n-\mathrm{BuOH}$. In order to focus on the trends in mechanical properties, the values are all normalized. In both cases, EtOH shows little change regardless of additive concentration, $n-\mathrm{PrOH}$ reaches a maximum at 3-5 vol.\% and $n-\mathrm{BuOH}$ reaches a maximum at 3 vol.\%. Note that the magnitude of both $U C S$ and $E$ is greatest in the case of $n-\mathrm{PrOH}$. Data is presented as the mean \pm one standard deviation of five measurements. 


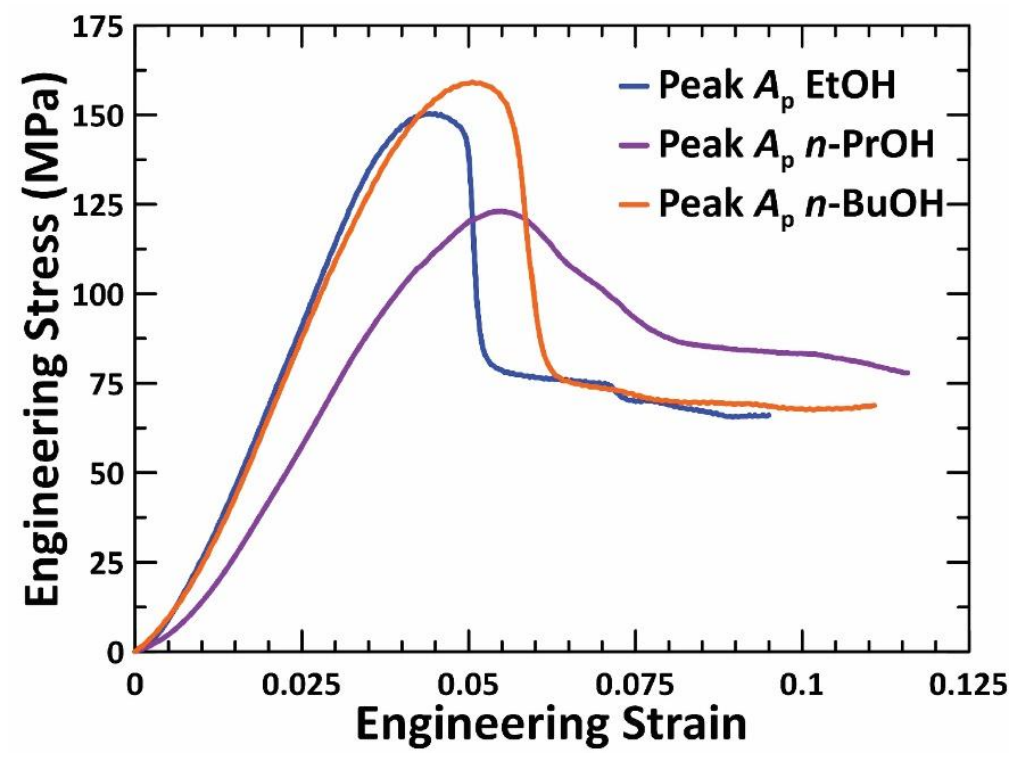

Fig. 11. Representative stress-strain curves from each of the peak $A_{\mathrm{p}}$ samples. It can be seen in all cases that initial failure occurs with little plasticity. However, the samples are still capable of maintaining a significant amount of stress after failure, thus increasing the toughness of the material. 


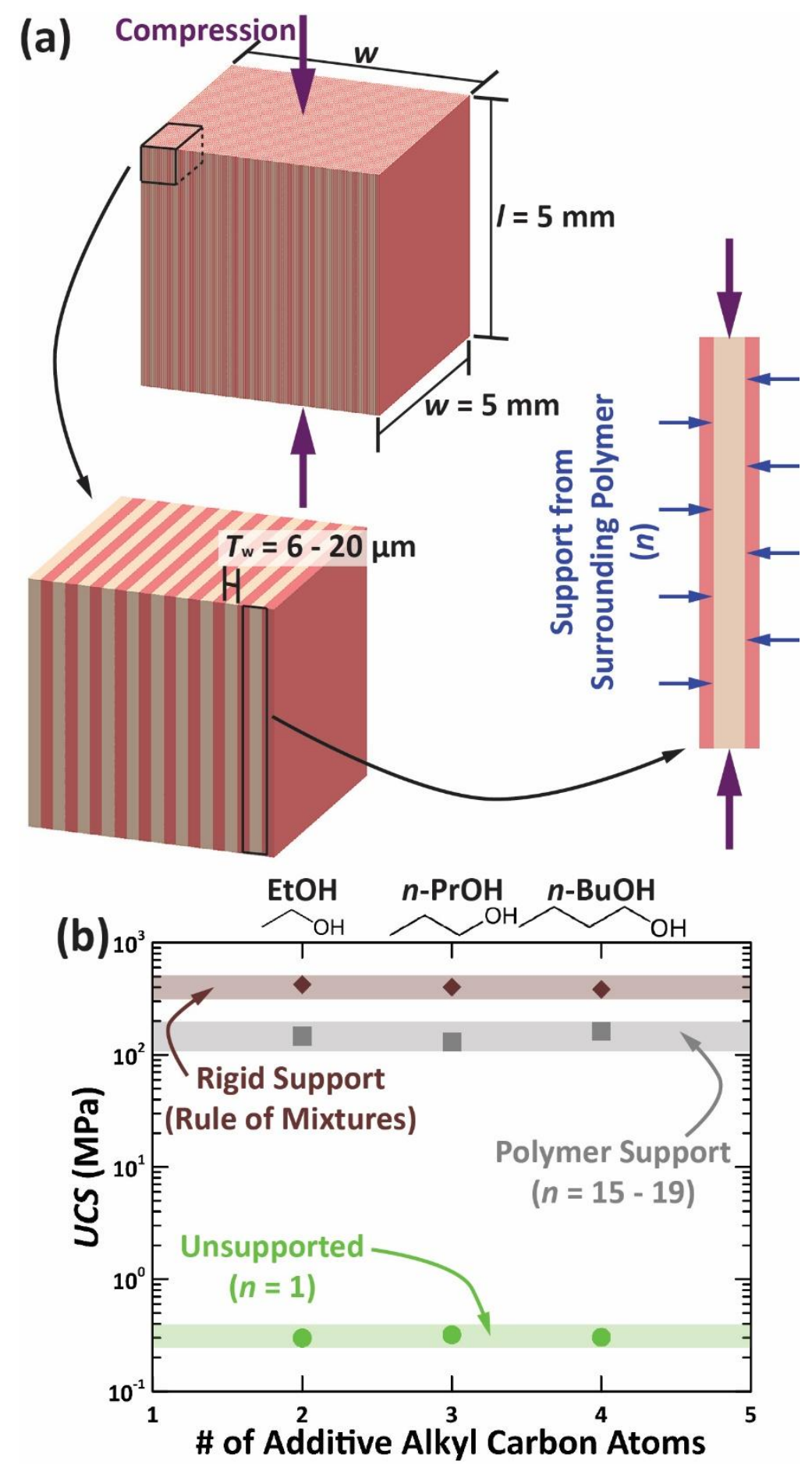

Fig. 12. Mechanical property analysis of the current bioinspired composites. (a) A simplified two-phase (polymer in pink and $\mathrm{ZrO}_{2}$ ceramic in yellow) layered composite model is considered using the experimentally measured geometric dimensions of $w, l$ and $T_{\mathrm{w}}$. The strength is considered to be a function of axial compression of the polymer phase and 
supported Euler buckling of the $\mathrm{ZrO}_{2}$ ceramic; (b) While the current bioinspired composites are unable to provide rigid support (as would be predicted by the rule of mixtures), they do provide significant buckling resistance, which is estimated to result in a buckling mode of $n=$ 15 - 19. This is orders of magnitude higher than the calculated strength of uninfiltrated, or unsupported, scaffolds $(n=1)$. 


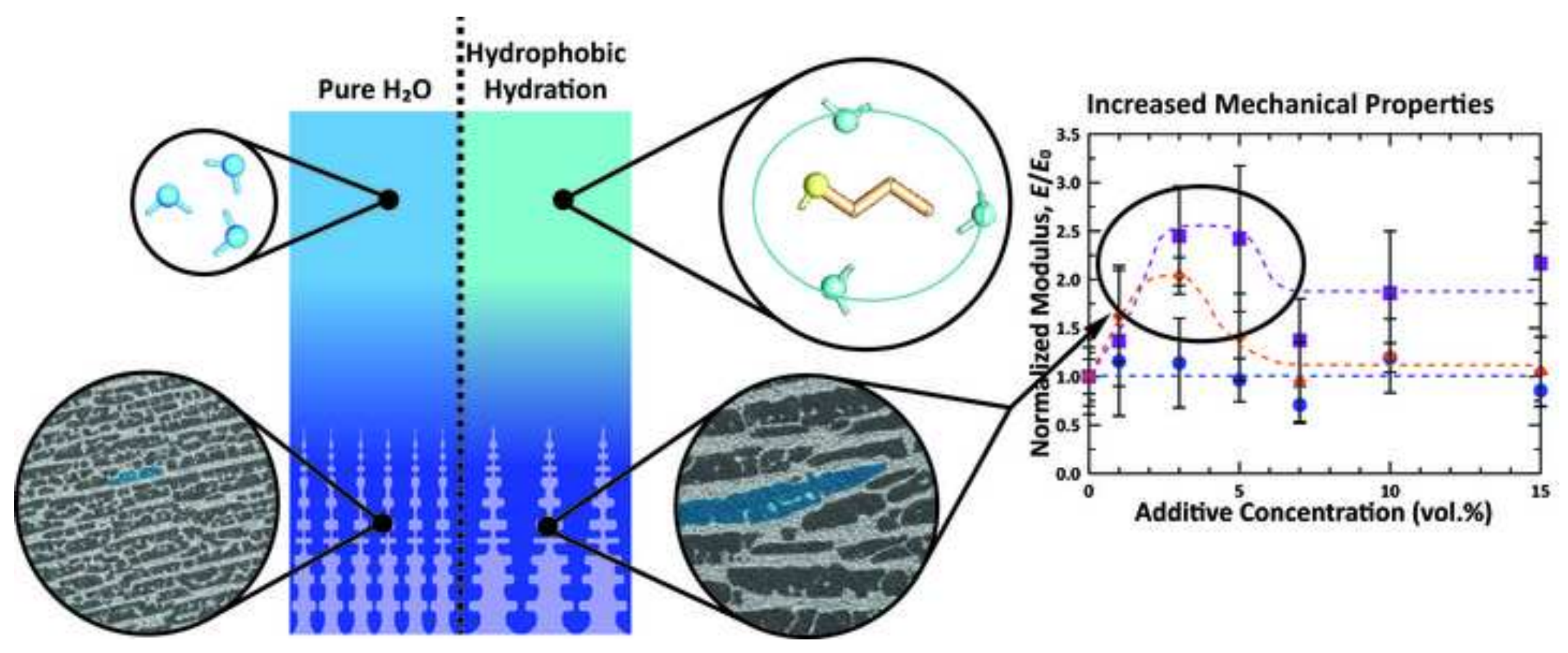

